Article

\title{
Hybrid LQR-PI Control for Microgrids under Unbalanced Linear and Nonlinear Loads
}

\author{
Gerardo Humberto Valencia-Rivera $₫$, Luis Ramon Merchan-Villalba $₫$, \\ Guillermo Tapia-Tinoco ${ }^{\circledR}$, Jose Merced Lozano-Garcia ${ }^{\circledR}$, Mario Alberto Ibarra-Manzano \\ and Juan Gabriel Avina-Cervantes *,+(i)
}

Telematics (CA), Engineering Division (DICIS), Campus Irapuato-Salamanca, University of Guanajuato, Carretera Salamanca-Valle de Santiago km $3.5+1.8$ km, Comunidad de Palo Blanco, Salamanca 36885, Mexico; gh.valenciarivera@ugto.mx (G.H.V.-R.); lr.merchanvillalba@ugto.mx (L.R.M.-V.); g.tapiatinoco@ugto.mx (G.T.-T.); jm.lozano@ugto.mx (J.M.L.-G.); ibarram@ugto.mx (M.A.I.-M.)

* Correspondence: avina@ugto.mx; Tel.: +52-4646-4799-40 (ext. 2400)

† Author thanks the Universidad de Guanajuato by the financial support of the APC.

Received: 11 June 2020; Accepted: 30 June 2020; Published: 4 July 2020

check for updates

\begin{abstract}
A hybrid Linear Quadratic Regulator (LQR) and Proportional-Integral (PI) control for a MicroGrid (MG) under unbalanced linear and nonlinear loads was presented and evaluated in this paper. The designed control strategy incorporates the microgrid behavior, low-cost LQR, and error reduction in the stationary state by the PI control, to reduce the overall energetic cost of the classical PI control applied to MGs. A Genetic Algorithm (GA) calculates the parameters of LQR with high-accuracy fitness function to obtain the optimal controller parameters as settling time and overshoot. The gain values of the classical PI controller were determined through the improved LQR values and geometrical root locus. When MG operates in the grid-tied mode under unbalanced conditions, the controller performance of the Current Source Inverter (CSI) of the MG is considerably affected. Consequently, the CSI operates in a negative-sequence mode to compensate for unbalanced current at the Point of Common Coupling (PCC) between the MG and the utility grid. The study cases involved the reduction of the negative-sequence percentage in the current at the PCC, mitigation of harmonics in the current signal injected by the MG, and close related power quality issues. All these cases have been analyzed by implementing an MG connected at the PCC of a low-voltage distribution network. A numerical model of the MG in Matlab/Simulink was implemented to verify the performance of the designed LQR-PI control to mitigate or overcome the power quality concerns. The extensive simulations have permitted verifying the robustness and effectiveness of the proposed strategy.
\end{abstract}

Keywords: microgrid; LQR-PI control; grid-tied mode; current imbalance; power quality; genetic algorithms

\section{Introduction}

Nowadays, fossil fuels are the primary source of energy worldwide, but the extensive use of this natural resource has caused an increase in the average temperature of the earth. Environmental organizations have the aim of gradually decoupling the use of fossil fuels from $70 \%$ to $20 \%$ in 2050 [1] Advances in the technology directed on the energy production area, environmental sustainability, and the appearance of small generation systems have opened new opportunities to research in Distributed Energy Resources (DERs). The DERs have raised an alternative solution to efficiently face the actual energy demand, centered on the reliability and energy quality [2]. Many consumers, such as buildings, factories, and residential neighborhoods, are planning to place a Microgrid (MG) 
considering the cost reductions in the technology associated with the DERs and storage systems, contributing simultaneously to reach a better energy quality [3]. MG is defined as an interconnected load group and DERs with boundaries clearly defined that act as a controllable entity concerning the grid [4]. MG is composed of essential components as the loads, DERs, Static Disconnect Switch (SDS), protections, digital communications, control, and automation systems [5].

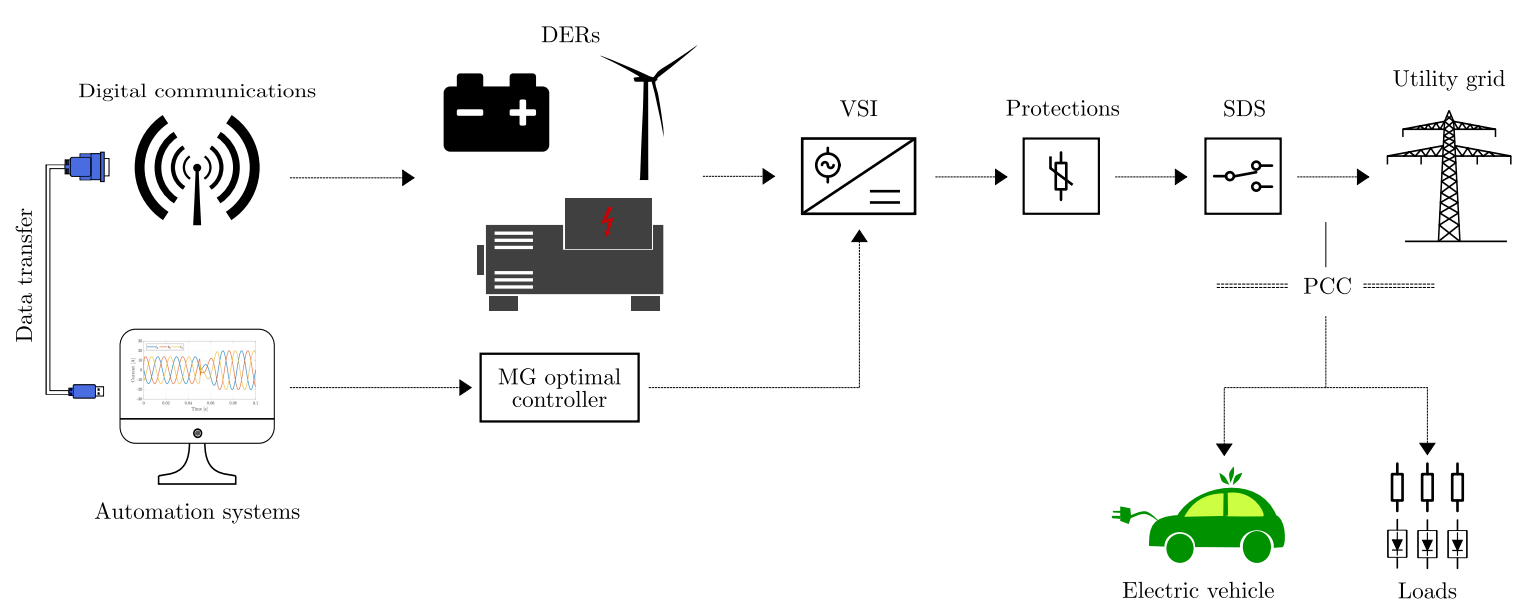

Figure 1. Basic operative elements composing a Microgrid (MG). A network of different power sources is distributed, administrated, and controlled at the same station to provide stable energy to any connected loads.

Figure 1 shows the essential components that integrate an MG. The MGs are defined as the small local distribution systems which promote the use of DERs. DERs are small energy units of generation and storage. These can come from renewable energy sources such as wind turbines, non-renewable energy sources such as diesel generators, or energy storage systems such as batteries. It has linear loads, non-linear loads, or dynamic loads such as electric vehicles. The MG operates in grid-tied mode or stand-alone mode. To achieve this, it has protections and control systems that allow connection and disconnection to the utility grid safely and without affecting its stability. Energy management is established through measurement and control systems. These systems allow the MG to operate with a decentralized or centralized control scheme, which has a direct impact on the MG's power quality and reliability. While MG operates in grid-tied mode, unbalanced loads or grid failures are originated by unbalanced currents and voltage at the Point of Common Coupling (PCC) affecting the energy quality index [6,7]. In our study, the SDS located at the PCC is assumed as closed. Hence, the MG is operating in grid-tied mode.

Likewise, MG voltage depends on the connections associated with the electric grid. Thus, unbalanced loads connected at the PCC provoke that the Current Source Inverter (CSI) may supply three-phase unbalanced currents with components of a negative-sequence directly towards the MG. This effect degrades the CSI performance and the energy quality index due to fluctuations in the inverter's current and power signals. In this way, negative-sequence components are generated in the measured current at the PCC, affecting the current balance percentage, ruled in the IEEE 1159-1995 standard [8]. Moreover, nonlinear loads introduce a band of harmonics into the MG, producing distorted waveforms at the current signal in the utility grid and CSI output. MG must attenuate such harmonics to avoid include perturbations on the system dynamics, as well as in the sensitive loads connected simultaneously at the PCC.

On the other hand, control approaches on MGs are focused on separating current and voltage signals from the negative and positive sequences in the CSI to address these electrical grid issues $[7,9,10]$. Obtained such a decomposition, a control law is designed for each of these components to increase the CSI control performance [11]. Several studies have proposed to improve the energy 
quality index by reducing the negative-sequence component of the control signals [12]. Dasgupta et al. worked on a current controller based on the Lyapunov function to control the active and reactive power flow to a three-phase MG system [13]. The Fault Current Limiter (FLC) is another methodology that suppresses fault currents from the utility grid, assuring the good operation of the MG. This tool seems to solve the over-current relay coordination issue in the MG [14]. Surrender et al. proposed a collaborative optimization framework, including the Differential Evolution (DE) and Harmony Search (HS) methods, to obtain the efficient energy resources distribution in the MG. The MG was composed of several renewable energy sources where the optimization processes involved energetic, economic, and environmental factors [15]. Lotfollahzade et al. used an LQR-PID controller optimized by PSO (Particle Swarm Optimization) to compute the proportional, integral, and derivative parameters to obtain an optimal load sharing of an electrical grid [16]. Savage et al. proposed to design hierarchical control techniques to enhance the energy quality in the connected bus at sensitive loads [17]. A primary control took DERs administration, and secondary control drove the voltage levels at the load bus by sending the control signals to the primary block for compensating the unbalances. Shi et al. tested a control strategy under three-phase unbalanced [10]. They proposed a unified three-phase voltage correction through negative-sequence compensation. In practice, dynamic systems need to use robust, versatile, and tunable control strategies, in that sense, the hybrid control is becoming a reliable alternative in automatic systems, especially in MG. Lindiya et al. adopt a conventional multi-variable PID and LQR algorithm in DC-to-DC converters for reducing cross-regulation [18]. For realistic simulation of MG performance, Momoh and Reddy present a platform to simulate basic MG using Hardware-In-Loop (HIL) under different environments [19]. This interesting tool allows testing divers controllers and measures the performance of the MG on delivering the power supply requirements under different scenarios.

In other related areas, Sen et al. tuned a hybrid LQR-PID controller to regulate and monitor the locomotion of a quadruped robot using the Grey-Wolf Optimizer (GWO) [20]. Besides, Nagarkar et al. proposed a PID and LQR control to optimize a nonlinear quarter car suspension system [21]. Ibrahim et al. integrate the dynamic behavior of an LQR-based PID controller applied to a helicopter control with three degrees of freedom [22]. In this article, an efficient control technique based on PI-LQR driven by a Genetic Algorithm (GA) and a high-accuracy fitness function is proposed to regulate the energy provided by an MR. A genetic algorithm warranties that LQR is behaving according to design requirements as settling time and overshoot of the transfer function modeling the MG. To reach the appropriate current and power values to be supplied by the MG, a PI control strategy is included in the optimized transfer function. In such a sense, the required characteristics are a low-cost operation of the system during LQR operation, and the error reduction in the steady-state while using the PI control.

Consequently, an LQR-PI control technique is proposed to conduct the control action of the CSI, so the operation can operate in the negative-sequence mode. Besides, this action helps to mitigate the negative-sequence components of the current signal injected by the MG, phenomena caused by unbalanced linear and nonlinear loads. On the other hand, the proposed control methodology reduces the harmonic distortion generated by nonlinear loads, which is computed by the Total Harmonic Distortion (THD). Moreover, such schemes guarantee the current equilibrium at the PCC, and an acceptable energy quality index according to the norm ruling the MGs. The significant contributions of this paper are to propose the GA with an effective and accurate fitness function that helps to calculate the controller design parameters and to hybridize the properties of PI and LQR controllers applied to the MG to provide the demands of energy. This methodology looks for improving quality energy issues considering the energetic cost of the system during its operation and compares the classical methods used to design PI controllers applied to MG.

\section{Microgrid Structure Analysis}

The MG configuration used in this work is shown in Figure 2. 


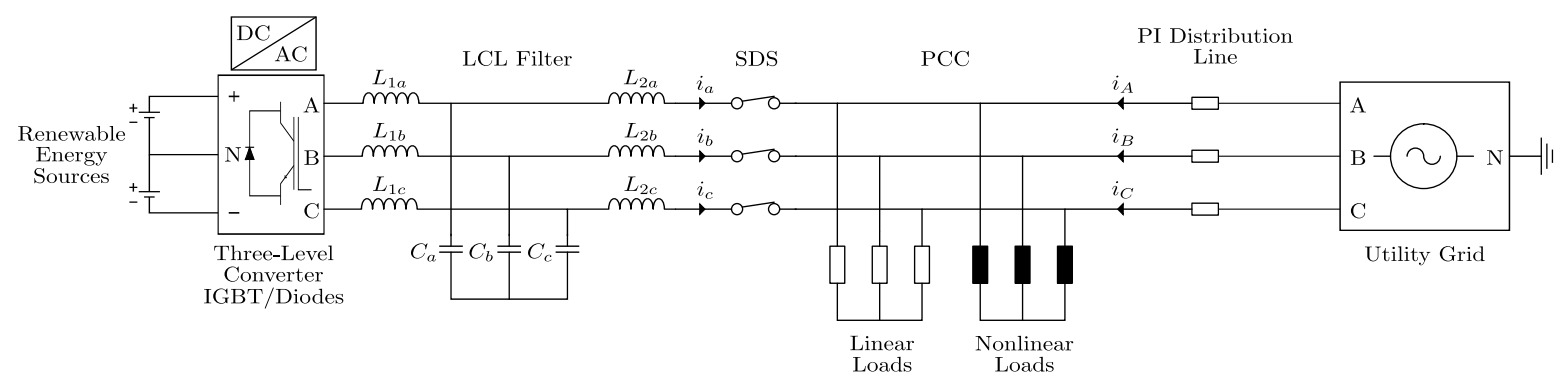

Figure 2. The Microgrid structure used in this work. CSI and LCL filter compound the operational controlled current source.

The utility grid is represented by a three-phase voltage source and its coupling impedance. The linear and nonlinear loads are connected at the common coupling point. In particular, linear loads have a three-phase configuration and operate with a unity power factor. Contrarily, nonlinear loads are modeled as controlled, single-phase current sources. This scheme allows controlling the harmonic content in each of the phases of the MG. Besides, the MG is connected to the PCC employing an SDS switch that is kept closed to operate in a grid-tied mode. Electrically, the MG is represented by an equivalent circuit consisting of a Renewable Energy Source (RES), a converter and a low-pass filter. An ideal voltage source serves to represent the RES because of its energy is directly taken from clean photovoltaic cells. Moreover, there are no associated mechanical components of inertia as in microturbines, wind turbines, among others [23]. The converter is in charge of performing the power transfer between the DC bus and the AC network. An LCL low-pass filter is required to attenuate the currents' high-frequency components provided by the MG $\left(i_{a}, i_{b}, i_{c}\right)$.

LCL filters have great advantages considering aspects as a reduced cost and size because the estimated values of the inductors are smaller than L and LC filters topology [24]. Besides, this efficient filter shows better performance on filtering high-frequency harmonics generated by the switching of PWM converters, including grid-connected converters controlled by the current sources [25]. In our study, the SDS that links the MG with the utility grid is considered closed because of MG is operated in grid-tied mode. This analysis considers that the MG provides active power to supply energy into the loads connected to the PCC. In case of failure or instability in the utility grid, the MG works as a support system injecting or consuming reactive power to balance the voltage at PCC. For such a purpose, the methodology seeks to control the currents by a set of inductors located just aside the PCC, considering that these elements deliver the power toward the utility grid directly.

In practice, the Park transformation is used for obtaining a simplified state-space model of the MG to dispose of a decoupled system representing the MG behavior [26]. First, the passive elements (inductors and capacitors) are considered to have the same value for each of the phases. Therefore, the three-phase representation of passive elements is given by

$$
L_{\alpha k}=l_{k} I_{3}, \quad C_{\alpha k}=c_{k} I_{3},
$$

where $I_{3}$ is the identity matrix of order $3, l_{k}$ and $c_{k}$ are the passive components' scalar values in each phase. Second, a framework mapping from the three-phase $a b c$ to the $d q$ domain is applied to the passive elements. Such a mapping is made by the well-known current-tension relations for inductors and capacitors as follows,

$$
\begin{aligned}
V_{a b c}^{L_{\alpha k}} & =L_{\alpha k} \frac{d}{d t} I_{a b c}^{L_{\alpha k}}, \\
I_{a b c}^{C_{\alpha k}} & =C_{\alpha k} \frac{d}{d t} V_{a b c}^{C_{\alpha k}} .
\end{aligned}
$$


Third, the Park transform $T_{p}(\theta)$ is then applied to Equations (2) and (3) to obtain an orthogonal rotating reference frame $(d q)$.

$$
\begin{aligned}
V_{d q}^{L_{\alpha k}} & =T_{p}(\theta) L_{\alpha k} \frac{d}{d t}\left(T_{p}(\theta)^{-1} I_{d q}^{L_{\alpha k}}\right), \\
I_{d q}^{C_{\alpha k}} & =T_{p}(\theta) C_{\alpha k} \frac{d}{d t}\left(T_{p}(\theta)^{-1} V_{d q}^{C_{\alpha k}}\right),
\end{aligned}
$$

where $\theta$ represents the axes turning-speed for a determined phase, and in the mapping framework, $\theta$ is defined by $\omega t$. Thus, $T_{p}(\theta)$ operator is well-known as the Park transformation. Finally, Equations (4) and (5) are solved using the chain rule with $\theta=\omega t$ to achieve the $d q$ model for each passive element,

$$
\begin{aligned}
v_{d}^{l_{k}} & =-\omega l_{k} v_{q}^{l_{k}}+l_{k} \frac{d}{d t} I_{d}^{l_{k}}, \\
v_{q}^{l_{k}} & =\omega l_{k} v_{d}^{l_{k}}+l_{k} \frac{d}{d t} I_{q}^{l_{k}}, \\
i_{d}^{c_{k}} & =-\omega c_{k} v_{q}^{c_{k}}+c_{k} \frac{d}{d t} V_{d}^{c_{k}}, \\
i_{q}^{c_{k}} & =\omega c_{k} v_{d}^{c_{k}}+c_{k} \frac{d}{d t} V_{q}^{c_{k}} .
\end{aligned}
$$

These foundations are mathematically represented by the state-space model given in Equations (10) and (11)

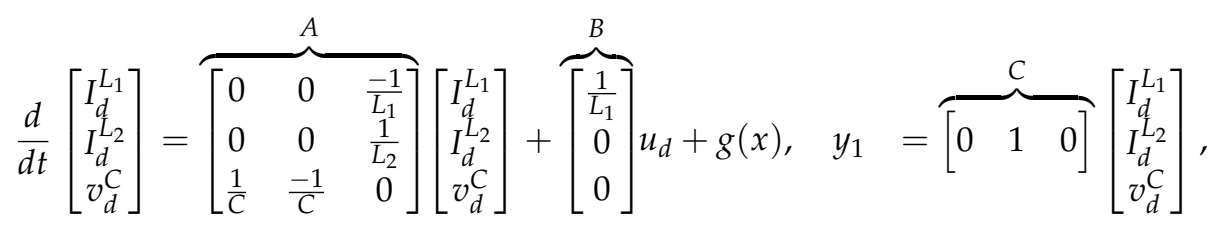

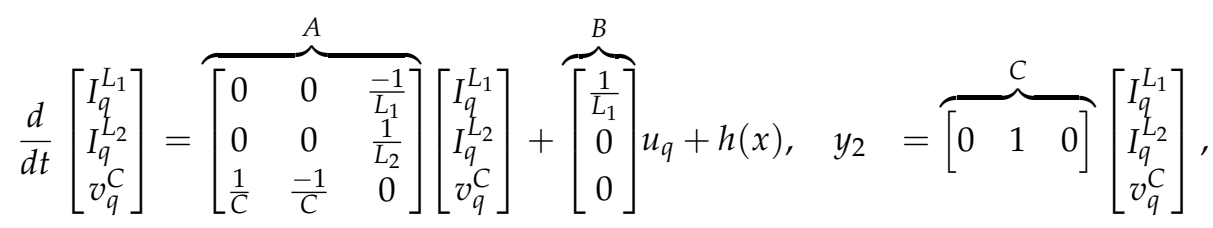

where $u_{d}$ and $u_{q}$ represent the $d q$ components of the input voltage source. The functions $g(x)$ and $h(x)$ are used to include the system response face to perturbations, which are modeled by Equations (12) and (13),

$$
\begin{aligned}
& g(x)=\left[\begin{array}{lll}
\omega & 0 & 0 \\
0 & \omega & 0 \\
0 & 0 & \omega
\end{array}\right]\left[\begin{array}{c}
I_{d}^{L_{1}} \\
I_{d}^{L_{2}} \\
v_{d}^{C}
\end{array}\right]-\left[\begin{array}{c}
0 \\
1 \\
L_{2} \\
0
\end{array}\right] V s_{d}, \\
& h(x)=-\left[\begin{array}{ccc}
\omega & 0 & 0 \\
0 & \omega & 0 \\
0 & 0 & \omega
\end{array}\right]\left[\begin{array}{c}
I_{q}^{L_{1}} \\
I_{q}^{L_{2}} \\
v_{q}^{C}
\end{array}\right]-\left[\begin{array}{c}
0 \\
\frac{1}{L_{2}} \\
0
\end{array}\right] V s_{q},
\end{aligned}
$$

where the active variables $V s_{d}$ and $V s_{q}$ represent the $d q$ components of the electrical grid signals. Such perturbations affect the system behavior meaningfully and whose effects must be reduced or eliminated. Indeed, our model is based on the state-space using the Park transformation to simplify the MG analysis so that it is possible to obtain two decoupled systems in the $d q$ framework [27]. The $d$ component controls the active power flow, whereas the $q$ component regulates the reactive power flow, respectively.

All MG interactions are formally described in the state-space system represented by Equations (10)-(13). In such a representation, $\frac{d}{d t} I_{d}^{L_{1}}, \frac{d}{d t} I_{q}^{L_{1}}, \frac{d}{d t} I_{d}^{L_{2}}, \frac{d}{d t} I_{q}^{L_{2}}, \frac{d}{d t} v_{d}^{C}$, and $\frac{d}{d t} v_{q}^{C}$ are the 
voltages in the inductors $L_{1 k}$ and $L_{2 k}$, as well as the current in the capacitor $C_{k}$ into the $d q$ framework, respectively. Similarly, $I_{d}^{L_{1}}, I_{q}^{L_{1}}, I_{d}^{L_{2}}, I_{q}^{L_{2}}$ are the inductor currents and $v_{d}^{C}, v_{q}^{C}$ are the capacitor voltages in the $d q$ reference frame. After estimating the system response, the results allow determining that the modeled MG is critically damped because the transfer function that describes the dynamic system has two complex-conjugated poles on the imaginary axis. In consequence, the method of states-feedback is applied to dispose of a more suitable allocation of the system poles, which will improve the response to the step input. New control law representation and the derived dynamics system are described by Equations (14) and (15)

$$
\begin{aligned}
& u(t)=r(t)-K \cdot x(t) \\
& \dot{x}(t)=(A-B K) \cdot x(t)+B \cdot r(t)
\end{aligned}
$$

where $u(t)$ is the system input, $r(t)$ is system reference, and $K$ represents the state feedback gains. The state vector can be calculated by the dominant pole placement technique, which consists of matching the system characteristic polynomial with a theoretical polynomial containing all needed control parameters (i.e., overshoot, rise time, settling time, among others). However, this technique presents a problem tied to the arbitrary pole assignment, which directly affects the control effort with inconvenient or impractical values in the gain matrix $K$. Therefore, the LQR algorithm was implemented and evaluated to address previous shortcomings in the analysis of the MG. The $K$ matrix is then optimally computed to find the best poles placement of the system [28]. The full state feedback control allows a suitable selection of the components describing the dynamics of the systems [29], in this case focused on controlling the MG where the design is driven by GA. The proposed diagram of full state feedback is shown in Figure 3.

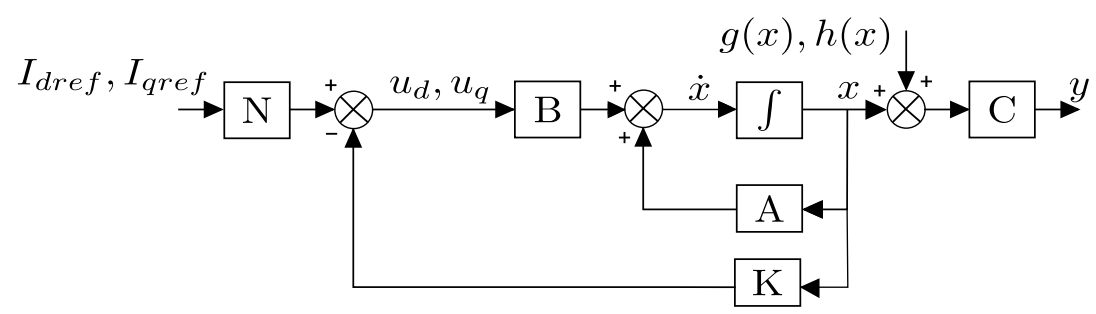

Figure 3. Full state feedback LQR-controller for the decoupled MG system.

In the diagram, matrices $\{A, B, C\}$ are the original system matrices in the state-space representation given by Equations (10) and (11), $K$ is the state feedback matrix, and the precompensation gain $N$ is a scaling factor that multiplies the system reference to achieve the output desired value $y=\left[y_{1}, y_{2}\right]^{\top}$. Indeed, the $N$ scaling factor is calculated by

$$
N=-\frac{1}{C[S I-(A-B K)]^{-1} B} .
$$

Additionally, the cost function required by the LQR algorithm to obtain the optimal control parameters is defined as follows,

$$
J=\int_{0}^{\infty}\left(X^{T} Q X+u^{T} R u\right) d t
$$

where $Q \geq 0, R>0$ are positive semi-definite matrices. $Q$ is the state matrix penalization, and $R$ expresses the actuator effort. The cost function $J$ is subject to the next system constraint,

$$
\dot{x}(t)=A x(t)+B u(t),
$$


where $x(t)$ and the $u(t)$ are vectors $\in \mathbb{R}^{n}$. Thus, the original system input and state vector are theoretically calculated by

$$
\begin{aligned}
u(t) & =-K x(t), \\
K & =R^{-1} B^{T} S .
\end{aligned}
$$

The LQR optimization problem requires firstly to solve the algebraic Riccati equation,

$$
A^{T} S+S A-S B R^{-1} B^{T} S+Q=0 .
$$

In some cases, the matrices $Q$ and $R$ could be assigned arbitrarily; unfortunately, the control design over the required system response could be compromised or impractical. Hopefully, to address those disadvantages, the Riccati equation allows assigning state penalization values that belong to matrix $Q$ and $R$ to modify the speed response of the LQR controller. Therefore, it is possible to compute the values of the matrix $K$ and the system input $u(t)$ by solving $S$ of Equation (21). However, when faster and more efficient system dynamics are required, the random parameters assignation in the matrix $Q$ and $R$ can lead to a second problem. In that case, the estimated values of matrices $Q$ and $R$ grow out of the allowed range to fulfill the control design requirements (e.g., settling time and overshoot) of the transfer function describing the MG. This issue is efficiently addressed by using an optimization method to compute the matrices $Q$ and $R$. Hence, a proper cost function, involving the overall design requirements of the transfer function jointly with the parameters of the LQR algorithm, is then minimized. For overcoming the issues of arbitrary pole placement, a genetic optimization algorithm was also proposed in this study, since this optimization technique can operate in parallel to find multiobjective solutions [30].

\section{Genetic Algorithms}

The genetic algorithms (GA) are metaheuristic algorithms belonging to the family of evolutionary algorithms (EA). All population-based algorithms work with a set of candidate solutions called phenotypes or population and a set of chromosomes representing the model's variables. Each candidate solution in the population is coded in a chain of chromosomes or genotypes. Since these algorithms are inspired in the natural selection, the chromosomes evolve throughout each iteration (i.e., generation) to produce new individuals (i.e., solutions). In each generation, the best chromosomes or individuals are selected by evaluating a suitable fitness function. The next generations are generated by applying a fundamental set of genetic operators until achieving the optimal result. The traditional chain of genetic operators comprises the initialization, crossover, mutation, and selection, as is shown in Figure 4.

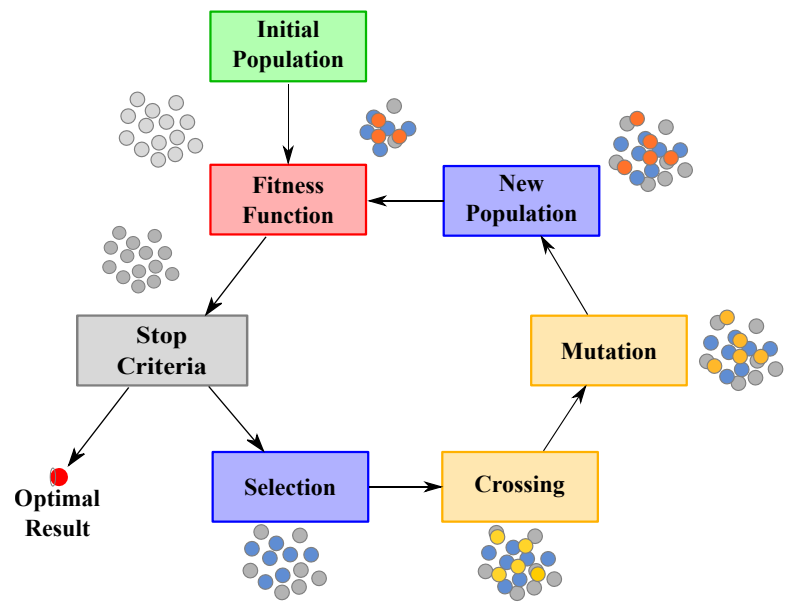

Figure 4. Flowchart of basic GA architecture used for tuning the LQR control. 
A new generation is processed when the requirements of a stop condition are not fulfilled [31]. A GA implementation could present many variations, which depends on the particular way of how each genetic operator is applied. The methodology driven by the GA to solve the energy cost issues based on the LQR controller is described by Algorithm 1.

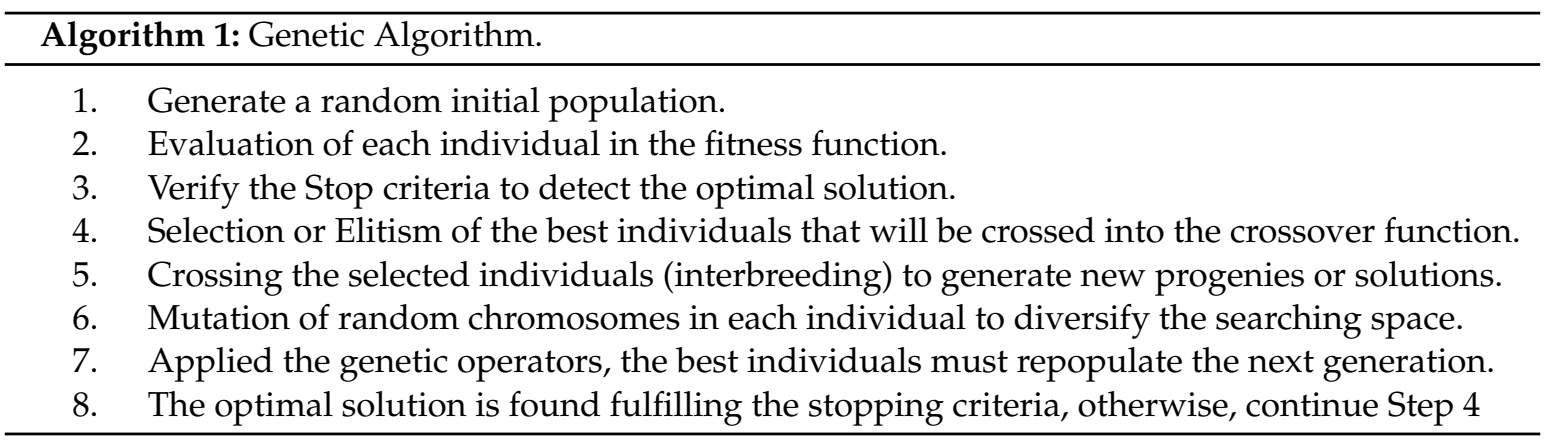

The GA starts with a random assignation of the chromosomes in each individual representing the variables of the proposed models. In this manner, each individual is a viable solution that must be further evaluated, and the overall initial individuals will form the initial population. In our implementation, the chromosomes represent the values of each element into the matrices $Q$ and $R$ as described next.

\subsection{Chromosome Configuration}

The proposed control modeled in real continuous variables led to select a floating-point representation of the chromosomes. In this case, bit string encoding mechanisms can be replaced for floating-point operations in the mutation and crossover functions. The chromosomes represent each variable to identify in the proposed control. In the proposed implementation, four chromosomes were used, three elements to describe the $Q$ matrix, and one element for the variable $R$ that internally are linked to the gains and poles in the system. It is noteworthy that such elements describe the control behavior while interacts with the MG. This controlling behavior is measured at the output by well-known design parameters (e.g., overshoot, settling time, undershot, stable error, rising time, or natural frequency). In the numerical simulations, settling time and overshoot factor were used in the fitness function. Hence, the chromosomes were coded in floating point, as well as the uniform distributions $U \in[0,1]$ were used to control the action of the morphological operators acting over chromosomes randomly selected. The initial population was fixed to $\mathrm{N}=100$.

\subsection{Mutation and Crossover}

Before mutation, the best suitable solutions (elite population) are selected and preserved. The elite population comprises the $5 \%$ of the total population, saving the fittest genetic material. The mutation operator using a floating-point representation is defined by

$$
x_{m}=(1-\alpha) * x_{j}+\alpha *\left(\left(X_{\max }-X_{\min }\right) * r_{u}+X_{\min }\right),
$$

where $\alpha=0.5, x_{j}$ is the chromosome randomly selected from the entire database $X$, which is mutated by a bounded interval $\left[X_{\min }, X_{\max }\right]$, and $r_{u}$ is a random number with uniform distribution $U \in[0,1]$. Hence, the algorithm was tuned to generate $20 \%$ of new chromosomes $x_{m}$. The mutation should produce new individuals with a probability of about $20 \%$ in our implementation. The crossover function used an unbalanced arithmetic operation defined mathematically as

$$
x_{c}=\left(1-r_{u}\right) * x_{i}+r_{u} * x_{j},
$$


where $r_{u}$ is a random number uniformly distributed $U \in[0,1], x_{i}$ is randomly selected between the best $25 \%$ of individuals and $x_{j}$ is randomly selected from last $75 \%$ in the prevailing population. Considering the elitism preserved $5 \%$ of the population, and the mutation provided $20 \%$, the crossing probability could be about $75 \%$.

The crossover and mutation probabilities are eventually modified depending on the individuals' fitness to achieve a good trade-off between exploration and exploitation. In fact, the mutation and crossover probabilities should slightly increase when the population is trapped into local optima, and such probabilities decrease when the population is too dispersed. In the order hand, there is no general consensus on how to measure and balance the exploration and exploitation efficiently in genetic algorithms [32]. In our implementation, this trade-off involves direct parameters of the algorithm, the number of generation and the population size, combined with the population diversity controlled by the crossover, mutation, and selection functions. Mutation and crossing explore a new solution with a conjoint probability of $P=0.2 \times 0.75=0.15$, and the exploitation uses basically the elitism function $P=0.05$, which express certain skew to the exploration in our implementation.

Finally, the GA selects the optimal solution for each chromosome (i.e., optimal matrices $Q$ and $R$ ) by using the appropriate cost function and the LQR algorithm, to achieve the desired behavior of the system.

\subsection{Fitness Function}

The fitness function is related to the error between the actual solution and the optimal solution, represented by the controlled MG behavior (i.e., overshoot and settling time) associated internally to the best chromosomes in the $Q$ y $R$ matrices. In control terms, the fitness function is related to signal error between the output and the set-point responses. However, computationally some parametric error could be used as Mean Absolute Error (MAE), Mean Squared Error (MSE), Mean Absolute Scaled Error (MASE), among others. The commonly used MSE merit function is highly affected by outliers, which produces undesirable results in some applications, such is the case of the proposed design. Therefore, the MAE function was used to cope with this disadvantage obtaining satisfactory results in the implemented GA algorithm. The MAE based on the $L_{1}$-norm is mathematically defined as

$$
\mathrm{MAE}=\frac{1}{N} \sum_{k=1}^{N}\left|y_{k}-\hat{y}_{k}\right|
$$

where $y_{k}$ is the actual value and $\hat{y}_{k}$ is the estimated behavior vector response of the proposed controlled model. This modest fitness function is really dependent on highly nonlinear parameters of the control interconnecting the grid, loads, and the power sources, which can be dynamically adjusted with the proposed GA optimization algorithm. Including the output control parameters of interest, the fitness function becomes,

$$
J=\left|W^{\top} *\left(X_{r e f}-X_{k}\right)\right|,
$$

where the vector $X_{r e f} \in\left[T_{s t} M_{o s}\right]^{\top}$ contains the desired parameters as the settling time $\left(T_{s t}\right)$ and the overshoot $M_{o s}$, and $W$ is a regularization (or scale) matrix to adjust the contribution and units of each kind of parameters. Besides, $X_{k}$ is the system's response parameters under the control action, while the chromosomes representing the control operational matrices $Q$ and $R$. The data used by the fitness function is computing by solving the dynamical model used to represent the control and the MG for each individual in the population. The weight matrix is defined as

$$
W=\left(\begin{array}{cc}
w_{1} / T_{s t}^{o} & 0 \\
0 & w_{2} / M_{o s}^{o}
\end{array}\right)
$$

where $w_{1}+w_{2}=1.0$ are the constants allowing to prioritize some of these output features, $T_{s t}^{o}$, and $M_{o s}^{o}$ are the maximum or actual values of the tested features to avoid dimensionality issues. The chosen 
fitness function is highly stable for the proposed model. It is worthy to notice that optimal $Q$ and $R$ matrices are highly dependent on the chosen fitness function, which could also be interpreted as an error function.

\section{LQR-PI Control Strategy for MG in Grid-Tied Mode}

Once computed the matrix $K$ driven by GA, the PI-LQR controller is designed to regulate the power flow from MG toward the utility grid. A robust and performing controller is obtained by combining the optimal properties of the LQR algorithm and a classical PI controller. Such a strategy allows achieving a bounded control action. Figure 5 illustrates the control action for the MG output voltages either to the hybrid PI-LQR controller, PI controller driven by GA, or PI controller tuned by the poles placement method. Control action values are into established parameters by MG voltage.

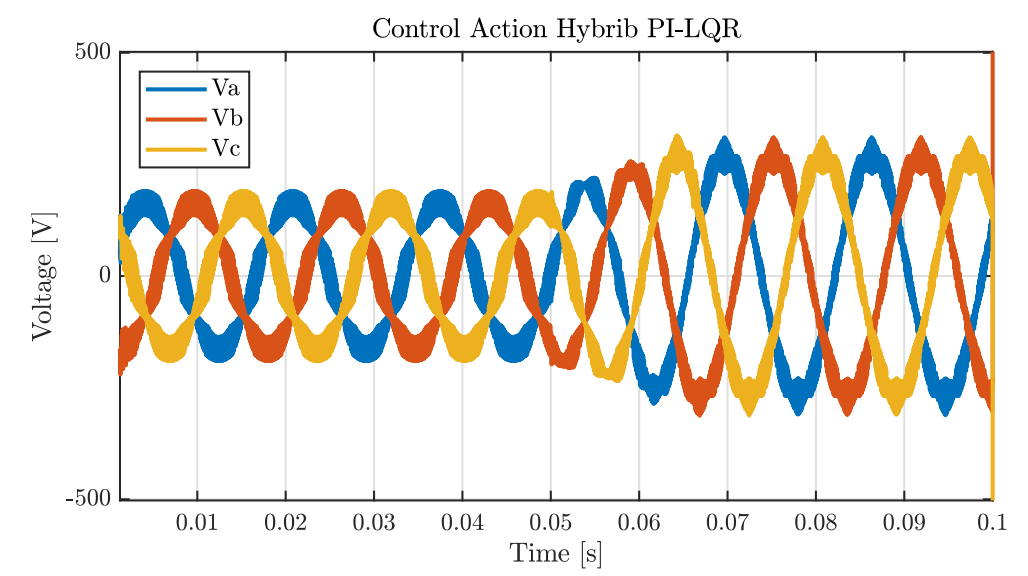

Figure 5. Illustrative voltage control action of the hybrid PI-LQR controller.

It is noticeable that the control action helps the system to recover and operate under established values for MG voltage (see Table 2). This signal controls the three-phases of the CSI switching-pattern to deliver the required power at the electrical grid. By the way, the controller's integral action also reduces the sensitivity face to perturbations, canceling the steady-state error for unit step inputs [33]. The PI control action is mathematically described by

$$
G_{c}(s)=K_{p}+K_{i} \frac{1}{s}=K_{p} \frac{s+K_{i} / K_{p}}{s}
$$

where $K p$ and $K i$ are the proportional and integral gains, respectively. All these gains were calculated by using the rlocus method, considering the suitable phase and magnitude conditions into the controller design. Figure 6 shows the optimal control scheme used to regulate the power flow at the PCC.

The instantaneous $P Q$ power theory is used to adjust the input references of the control system in the model shown in Figure 6. Such theory is based on a set of instantaneous powers defined in a temporal framework that imposes no constraints on the voltage or current waveforms. Thus, the same approach can be applied to three-phase systems with or without neutral wire [26]. In the proposed solution, the Park transform should be applied to convert the state-system from a three-phase framework (sinusoidal variables) to the $d q 0$ orthogonal reference system (constant values). Park transform allows synthesizing and decoupling the variables and associated states forming the MG. In this sense, the input references' values are obtained using the $P Q$ theory and Park transformation by

$$
\begin{aligned}
P & =\frac{3}{2} \times\left(V_{d} \cdot I_{d}+V_{q} \cdot I_{q}\right) \\
Q & =\frac{3}{2} \times\left(V_{q} \cdot I_{d}-V_{d} \cdot I_{q}\right) .
\end{aligned}
$$


Thus, the control signals are transformed into the three-phase frameworks for regulating the PWM signals into the three-level converters. Since PWM signals control the switching sequence of CSI, the model produces the desired power that the MG must inject toward the utility grid.

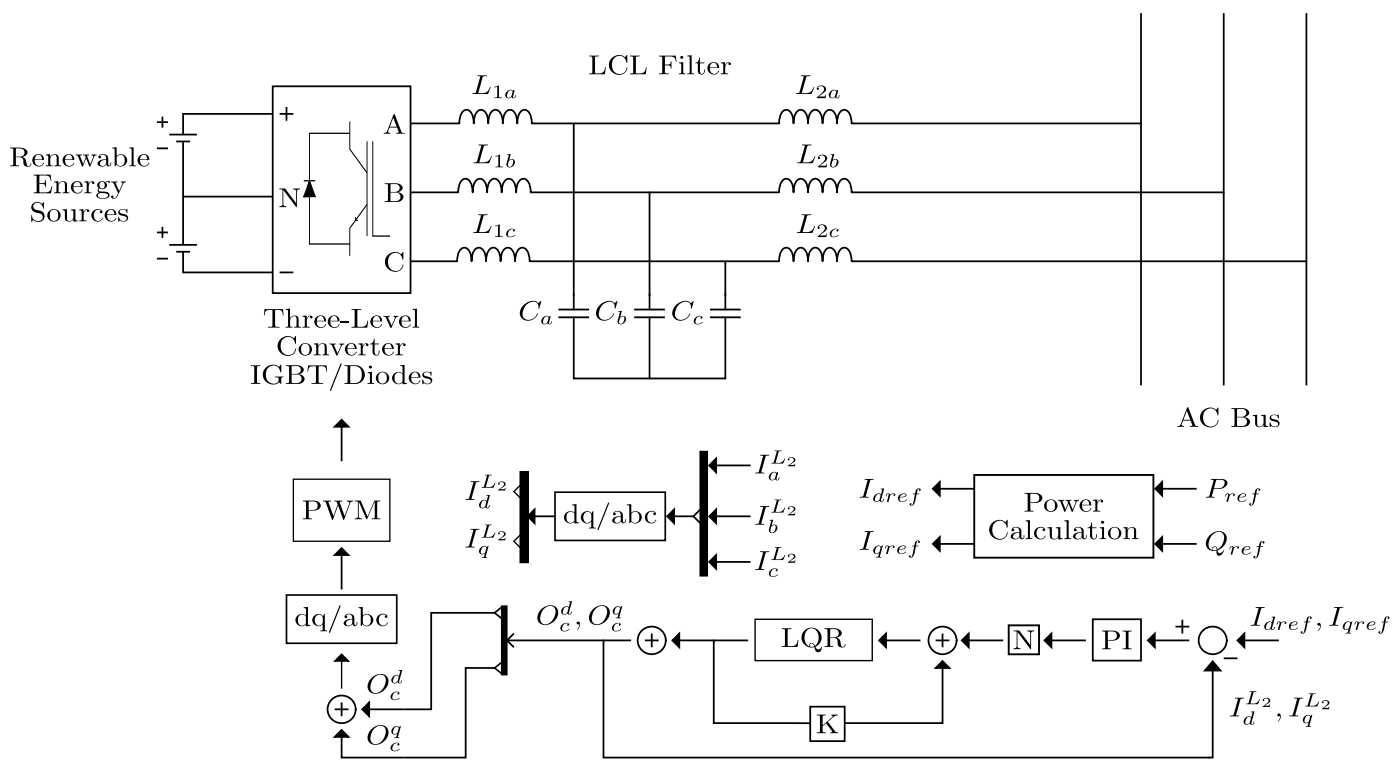

Figure 6. Optimal control scheme of a three-level converter in compensation mode.

\section{Energy Quality Index Applied to the Current Signal at the PCC}

Low voltage systems include linear and nonlinear single-phase, two-phase, and three-phase loads. These loads cause the system to become unbalanced, and consequently, the current and voltage waveforms of three-phase sources are not identical in magnitude and phase. Unfortunately, some electrical machines depend on a balanced power supply to avoid affectation on their functionality and performance [34]. When the MG operates in grid-tied mode, the failure generally comes from the utility grid and unbalanced loads resulting in three-phase unbalanced voltage at the PCC. However, the unbalanced factor could be quantified in a three-phase unbalanced system by using the symmetrical sequences approach. Such a method decomposes the unbalanced system into three sequence components, called the positive, negative, and homopolar sequences. This unbalanced percentage is calculated by the ratio of the negative and positive-sequences, which is formally known as voltage unbalance factor (VUF) and defined by Equation (30),

$$
\mathrm{VUF}=\frac{\left|V_{\sec (-)}\right|}{\left|V_{\sec (+)}\right|} \times 100[\%],
$$

where $V_{\sec (-)}$ and $V_{\sec (+)}$ are the negative and positive sequence components, respectively; both voltages are measured at the PCC. Similarly, the definition of VUF could be adopted to measure the current unbalance factor CUF, which is given by

$$
\mathrm{CUF}=\frac{\left|I_{\sec (-)}\right|}{\left|I_{\sec (+)}\right|} \times 100[\%],
$$

where $I_{\sec (-)}$ and $I_{\sec (+)}$ are the negative and positive sequence components, respectively; both currents are measured at the PCC. The currents $I_{s e c}$ are measured at the inductor bank $L_{2 k}$ of the MG through the sequence analyzer, where $L_{2 k}=\left\{L_{2 a}, L_{2 b}, L_{2 c}\right\}$. Our approach uses CUF because the designed control strategy is based on a current control loop. Thus, the CUF index is computed with the current signals provided by the MG at the PCC. Otherwise, linear, and nonlinear unbalanced loads may produce excessive levels of unbalanced current and voltages that tend to appear in the MG. These phenomena' 
main effects are lower performance, energy losses, and instability of the MG [35]. In the presence of negative-sequence components, the power electronics converters and induction motors cannot work or perform poorly [36]. An unbalanced voltage can produce an unbalanced current from 6 to 10 times the magnitude of the unbalanced voltages. Unbalanced currents can provoke excessive heat in the motor windings, leading to permanent damage [37]. The IEEE 1159-2009 standard establishes that the current unbalance recommended for monitoring power electronics, in steady-state, should be between $1 \%$ and $30 \%[8]$.

Another phenomenon affecting MG behavior is the increased use of nonlinear power electronic devices and sensitive loads [38]. These devices induce harmonics that may degrade the components either in the utility grid or MG. High-frequency harmonics can be filtered by passive or active filters, but the low-frequency harmonics are difficult to filter without reducing the system's operating frequency. There exist methods to mitigate the low-frequency harmonics, but these techniques are expensive and difficult to implement [39]. The current or voltage distortion is measured through Total Harmonic Distortion (THD), such index is applied to the voltage or current as follows,

$$
\begin{aligned}
\mathrm{THD}_{V} & =\frac{1}{V_{1}} \sqrt{\sum_{k=2}^{N} V_{k}^{2}} \times 100[\%], \\
\operatorname{THD}_{I} & =\frac{1}{I_{1}} \sqrt{\sum_{k=2}^{N} I_{k}^{2}} \times 100[\%] .
\end{aligned}
$$

THD is defined as the ratio of all root-sum-square of all harmonics (excluding the fundamental) divided by the fundamental [40]. The typical limit used in low-tension is about $5 \%$ of THD. In this study, the THD index is applied over the current signal delivered by the MG to evaluate the control performance face to harmonics generated by unbalanced nonlinear loads connected at the PCC.

\section{MG Control System Design}

Three optimal controllers were designed and analyzed to obtain the best response considering criteria as low-cost energy, mitigation of negative-sequence, and harmonics reduction. Low-cost energy criterion is directly associated either with the input source voltage or with MG voltage. In other words, such value expresses the energy required by the system to execute the control action over the injected current by MG, considering the respective estimations of $Q$ and $R$ matrices, the state feedback matrix $K$, and the control PI parameters $K_{p}$ and $K_{i}$. For each one of the designed controllers, three study cases were set up to evaluate the performance of the control schemes, which fulfilled the design criteria given initially. Proposed three study cases are based on making MG operate under the next conditions:

1. MG faces balanced nonlinear loads, the harmonics and negative sequence attenuation are analyzed.

2. MG works under unbalanced nonlinear loads, the harmonics and negative sequence mitigations are studied.

3. MG handles the unbalanced linear and nonlinear loads simultaneously; the attenuation of harmonics and negative sequence are both quantified.

The LQR algorithm is used to estimate the gains of feedback states driven by the GA method. Likewise, a PI controller was tuned to reach a robust control technique designed in all study cases. The design parameters of the LQR controller include a settling time, $T_{S}=0.525 \mathrm{~ms}$, and an overshoot of $5 \%$. For simulation purposes, the MATLAB/Simulink environment was used to evaluate the proposed MG control system. 


\subsection{Hybrid PI-LQR Control Driven by GA}

GA implementation starts tuning the initial values of all chromosomes. Each chromosome represents a potential solution to the weights of matrices $Q$ and $R$, which eventually adjust the controller's desired behavior. In the proposed model, the fitness function (see Section 3.3) performs the quality measure or associated error to each set of chromosomes representing each potential solution. The LCL filter parameters are given in Table 2. Such parameters are constant for all study cases and represented in the state space system given in Equations (10) and (11). The control parameters obtained from LQR driven by the GA, are estimated by,

$$
Q=\left[\begin{array}{ccc}
1.7042 & 0 & 0 \\
0 & 8644.6 & 0 \\
0 & 0 & 7.4115
\end{array}\right], K=\left[\begin{array}{r}
48.2624 \\
360.3162 \\
34.4453
\end{array}\right]^{\top}
$$

Besides determining $Q$ and $K$ matrices, the pre-compensation gain $N=408.5786$ and parameter $R=0.0518$ were also estimated. Those values were simulated in the proposed model to achieve an output settling time $T_{s}=0.52454 \mathrm{~ms}$ and an overshoot of $4.4643 \%$. The parameters utilized by GA for tuning the established criteria of the LQR algorithm are summarized in Table 1.

Table 1. GA-LQR Simulation Parameters.

\begin{tabular}{lc}
\hline GA Parameters & Value/Method \\
\hline Population Size & 100 \\
Max. Generations & 200 \\
Stop Criteria & 0.01 \\
Elitism & $5 \%$ of Population Size \\
Mutation Method & Aleatory Alteration \\
Crossover Method & Based on a Point \\
\hline
\end{tabular}

After tuning the parameters of the LQR method, the $K_{p}$ and $K_{i}$ PI controller parameters are determined through the rlocus method. A contribution of this study is to combine two control design methodologies to propose a hybrid PI-LQR controller, whose performance was tested on the MG model using Simulink. The utility grid is represented in the simulation model by its Thevenin equivalent (i.e., a three-phase electric source and the coupling impedance). The MG is integrated by a passive filter with topology L-C-L (Inductor-Capacitor-Inductor), a three-phase inverter based on IGBT technology controlled by the current loops $\left(I_{d}\right.$ and $\left.I_{q}\right)$, and the DC bus, which is powered by a voltage source. For all study cases, the current references for $d q$ components were set at $I_{d}=20 \mathrm{~A}$ and $I_{q}=0$. MG simulation parameters for the hybrid PI-LQR controller are shown in Table 2.

Table 2. Parameters of the MG model.

\begin{tabular}{lcc}
\hline Parameter & Value & Units \\
\hline MG Voltage $\left(V_{D C}\right.$ Figure 2$)$ & 311 & {$[\mathrm{~V}]$} \\
Filter Inductance & 2 & {$[\mathrm{mH}]$} \\
Filter Capacitance & 60 & {$[\mu \mathrm{F}]$} \\
Switching Frequency & 10 & {$[\mathrm{kHz}]$} \\
Proportional Constant $\left(K_{p}\right)$ & 0.27084 & \\
Integral Constant $\left(K_{i}\right)$ & 4289.948 & \\
Balanced 3-phase linear loads & $20 / 20 / 20$ & {$[\Omega]$} \\
Unbalanced 3-phase linear loads & $20 / 5 / 1$ & {$[\Omega]$} \\
Fundamental Frequency & 60 & {$[\mathrm{~Hz}]$} \\
\hline
\end{tabular}


Figure 7 shows the numerical results corresponding to the MG operation under the action of either (1) the hybrid PI-LQR controller, (2) the PI controller driven by GA, or (3) the PI controller designed by the poles placement technique, under the same operating conditions (linear balanced loads).

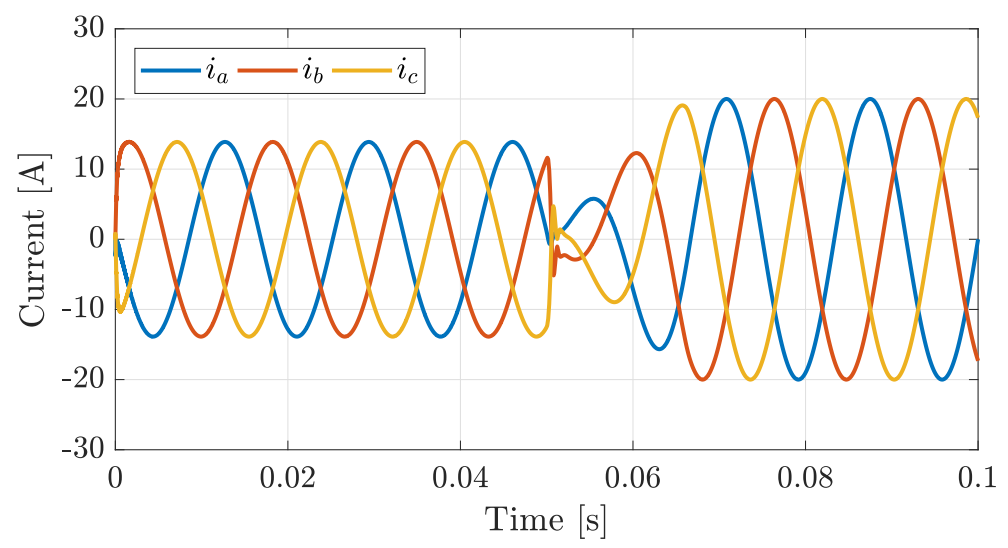

Figure 7. Simulation of three controllers designed to face a balanced linear loads interaction. The analysis is focused on measuring the reactions of the MG currents $\left\{i_{a}, i_{b}, i_{c}\right\}$.

The graphical responses of such controllers are equivalent. It is noteworthy that the controller is intentionally inactive in the initial interval of time, $0<t<0.05 \mathrm{~s}$, to have a reference for checking the posterior control action, as shown in Figure 7. The current flows from the utility grid towards MG during this time interval, so the MG is consuming power. The controller starts to operate since $t=0.05 \mathrm{~s}$, which produces a transitory response ending at $t=0.066 \mathrm{~s}$. In this period, the MG current reaches the reference current $\left(I_{d}=20 \mathrm{~A}\right.$ and $\left.I_{q}=0 \mathrm{~A}\right)$.

Moreover, the MG tracks the set-point until the desired current amplitude is injected into the system $\left(I_{a}=20 \mathrm{~A}, I_{b}=20 \mathrm{~A}\right.$, and $\left.I_{c}=20 \mathrm{~A}\right)$. The system was analyzed under ideal balanced conditions, including linear loads from simulated starts. This test is a start-up test of the hybrid PI-LQR controller working under normal operating conditions to demonstrate the method's correct operation. The same simulation is used for all study cases regarding the times of activation and deactivation of the hybrid PI-LQR controller. Figure 8 shows the performance of the action of either hybrid PI-LQR controller, PI controller driven by GA, or PI controller by poles placement under the presence of unbalanced linear loads.

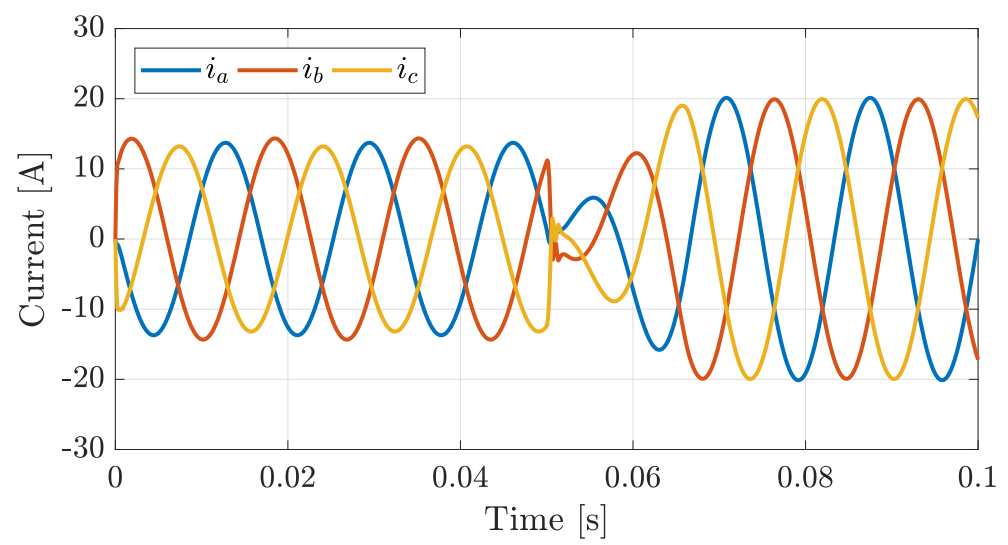

Figure 8. Simulation of three optimal controllers designed to face a unbalanced linear loads interaction.

The analysis is focused on measuring the reactions of the MG currents $\left\{i_{a}, i_{b}, i_{c}\right\}$.

Considering the same operating conditions and equivalent control responses because of the differences of such controllers are studied, respect the energetic cost, negative sequence mitigation, and harmonics attenuation. Remarkably, a CUF index of 9\% was reached when the controllers are 
disabled, but a CUF index of $1 \%$ is obtained when the controllers are under operation for unbalanced linear loads. The MG behavior is evaluated by connecting balanced nonlinear loads at the PCC to test control robustness. The nonlinear loads implemented in the simulations consist of three single-phase uncontrolled rectifiers. For such a case, the magnitude of the harmonics is calculated by $h_{c}=\frac{I_{\alpha}}{h_{o}}$, where $I_{\alpha}$ is the current of the fundamental component for each phase, and $h_{o}$ is the harmonic order. Figure 9 shows the current correction of the distorted current waveform, which was affected by operating under balanced nonlinear conditions. The amplitudes of the fundamental nonlinear load currents are $I_{a, 1}^{L}=20 \mathrm{~A}, I_{b, 1}^{L}=20 \mathrm{~A}$, and $I_{c, 1}^{L}=20 \mathrm{~A}$ for the balanced case.

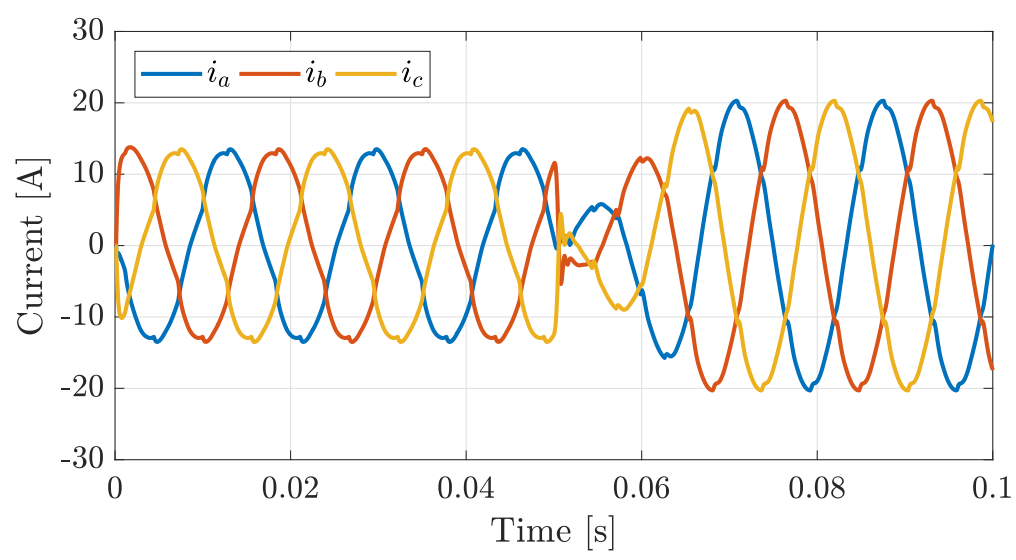

Figure 9. Current correction by the hybrid PI-LQR control action under balanced nonlinear load conditions.

Additionally, an FFT analysis was applied to obtain the spectral component of the current signal for studying the $\mathrm{THD}_{I}$ index behavior for each phase. From this analysis, the $\operatorname{THD}\left(i_{a}\right)=5.08 \%$, $\operatorname{THD}\left(i_{b}\right)=5.08 \%$, and $\operatorname{THD}\left(i_{c}\right)=5.08 \%$ indexes are obtained when the controller is disabled. Contrarily, the $\operatorname{THD}\left(i_{a}\right)=2.51 \%, \operatorname{THD}\left(i_{b}\right)=2.51 \%$, and $\operatorname{THD}\left(i_{c}\right)=2.51 \%$ indexes are reached when the hybrid PI-LQR control is activated. Besides, the harmonics of the 5th and 7th order are substantially attenuated for balanced nonlinear loads; such results are included in the second and third columns in Table 3.

Table 3. Harmonics content attenuated by hybrid PI-LQR controller.

\begin{tabular}{|c|c|c|c|c|c|c|}
\hline \multirow[b]{2}{*}{$\begin{array}{l}\text { Harmonics } \\
\left(I_{a}^{L}, I_{b}^{L}, I_{c}^{L}\right)\end{array}$} & \multicolumn{2}{|c|}{ Balanced Nonlinear Loads } & \multicolumn{2}{|c|}{ Unbalanced Nonlinear Loads } & \multicolumn{2}{|c|}{$\begin{array}{l}\text { Unbalanced Linear and } \\
\text { Nonlinear Loads }\end{array}$} \\
\hline & $\begin{array}{l}\text { Original } \\
\text { Currents }\end{array}$ & $\begin{array}{c}\text { Controlled } \\
\text { Currents }\end{array}$ & $\begin{array}{l}\text { Original } \\
\text { Currents }\end{array}$ & $\begin{array}{l}\text { Controlled } \\
\text { Currents }\end{array}$ & $\begin{array}{l}\text { Original } \\
\text { Currents }\end{array}$ & $\begin{array}{c}\text { Controlled } \\
\text { Currents }\end{array}$ \\
\hline Third & $0.00,0.00,0.00$ & $\begin{array}{l}0.00,0.00 \\
0.00\end{array}$ & $0.58,1.29,1.86$ & $\begin{array}{l}0.21,0.43 \\
0.52\end{array}$ & $0.40,1.00,1.32$ & $\begin{array}{c}0.20,0.35 \\
0.39\end{array}$ \\
\hline Fifth & $0.52,0.52,0.52$ & $\begin{array}{l}0.31,0.31 \\
0.31\end{array}$ & $0.10,0.80,0.74$ & $\begin{array}{l}0.15,0.44 \\
0.36\end{array}$ & $0.21,0.67,0.47$ & $\begin{array}{l}0.15,0.35 \\
0.21\end{array}$ \\
\hline Seventh & $0.38,0.38,0.38$ & $\begin{array}{l}0.26,0.25 \\
\quad 0.25\end{array}$ & $0.20,0.43,0.53$ & $\begin{array}{l}0.16,0.37 \\
0.41\end{array}$ & $0.05,0.32,0.37$ & $\begin{array}{l}0.01,0.24 \\
0.24\end{array}$ \\
\hline Ninth & $0.00,0.00,0.00$ & $\begin{array}{l}0.00,0.00 \\
0.00\end{array}$ & $0.26,0.33,0.12$ & $\begin{array}{l}0.28,0.30 \\
0.14\end{array}$ & $0.22,0.27,0.13$ & $\begin{array}{l}0.22,0.24 \\
0.13\end{array}$ \\
\hline Eleventh & $0.15,0.15,0.15$ & $\begin{array}{l}0.18,0.18 \\
0.18\end{array}$ & $0.12,0.15,0.13$ & $\begin{array}{l}0.16,0.14 \\
0.11\end{array}$ & $0.10,0.17,0.17$ & $\begin{array}{l}0.11,0.18 \\
0.16\end{array}$ \\
\hline
\end{tabular}

In the same context, a study case concerning an unbalanced nonlinear load was analyzed to test the MG performance. Here, the amplitudes of the fundamental unbalanced nonlinear load currents are given by $I_{a, 1}^{L}=6 \mathrm{~A}, I_{b, 1}^{L}=24 \mathrm{~A}$, and $I_{c, 1}^{L}=120 \mathrm{~A}$.

In the simulation, the CUF produced by the unbalanced nonlinear loads preserves the CUF ratio considered in the unbalanced linear load's study case. Figure 10 shows the distorted waveforms belonging to the current signals that lost the original sinusoidal shape under the effect of nonlinear loads. 


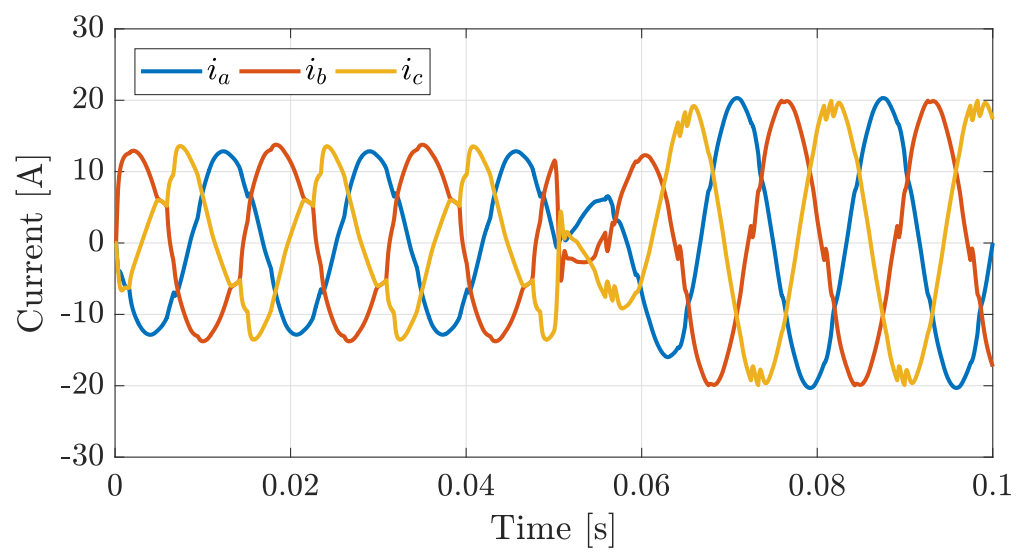

Figure 10. Current correction by the hybrid PI-LQR control action under unbalanced nonlinear load conditions.

However, activated the hybrid PI-LQR controller, the current signal is gradually improved and balanced by the action of the MG control. The CUF index produced by the unbalanced nonlinear loads was $11 \%$, but by using the hybrid control, this index was improved to $1 \%$. Similarly, a harmonics study was implemented to analyze the effects of unbalanced nonlinear loads over the current signal injected by MG. Table 3 (four and five columns) shows the harmonics reduction behavior under unbalanced nonlinear loads, which leads to reduce the $\operatorname{THD}\left(i_{a}\right), \operatorname{THD}\left(i_{b}\right), \operatorname{THD}\left(i_{c}\right)$ indexes from $5.47 \%, 11.83 \%$, and $18.39 \%$ to $2.49 \%, 4.63 \%$, and $4.61 \%$, respectively.

Finally, the case of unbalanced linear and nonlinear loads connected simultaneously at the PCC is studied. Figure 11 presents the result of the hybrid PI-LQR controller operation under the actions of both loads.

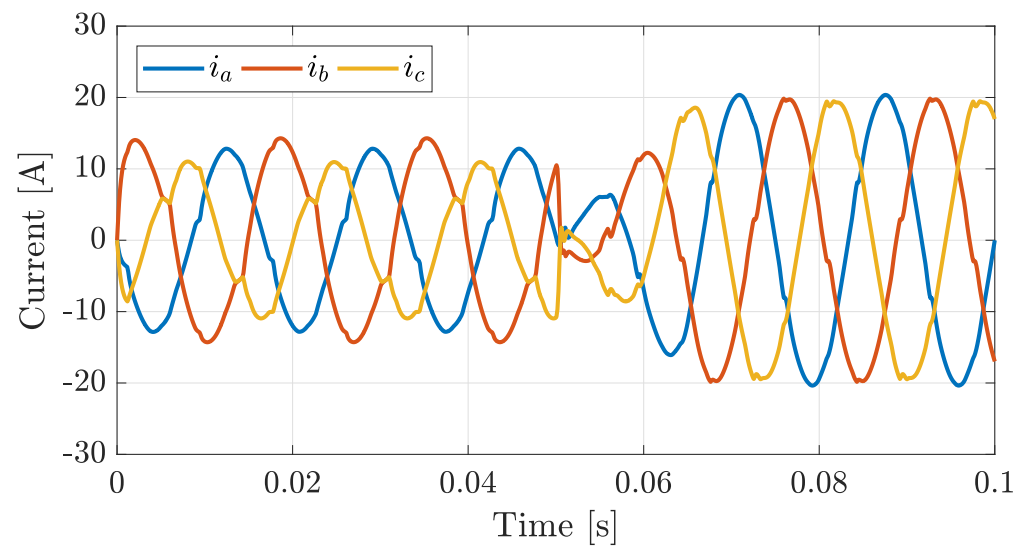

Figure 11. Current correction by the hybrid PI-LQR control action under unbalanced linear and nonlinear load conditions.

In this case, a high CUF $=18 \%$ index is obtained while the control is deactivated. Once the controller is activated, the CUF is reduced to $2 \%$. As in the unbalanced nonlinear load case, a significant reduction of harmonics was obtained, and the results are included in Table 3 (six and seven columns). THD indexes $\left(i_{a}, i_{b}\right.$ and $\left.i_{c}\right)$ were reduced from $4.39 \%, 9.15 \%$ and $14.31 \%$ to $2.11 \%, 3.39 \%$ and $2.97 \%$ for this study case.

\subsection{PI Controller Driven by GA and Rlocus Design}

The GA was implemented for tuning the matrix $K$ in the rlocus method (poles placement method). In this case, only one chromosome $(\alpha)$ was used together with the design parameters as the undamped 
natural frequency $\left(\omega_{n}\right)$, settling time $\left(T_{s}\right)$, damping factor $(\zeta)$, and overshoot $\left(O_{v}\right)$ to calculate the components of $K$. Therefore, the matrix $K$ could be estimated by

$$
K=\left[\begin{array}{c}
L_{1}(\alpha+2) \omega_{n} \zeta \\
\alpha C_{1} L_{1} L_{2} \omega_{n}^{3} \zeta-K_{1} \\
C_{1} L_{1}\left(2 \alpha \zeta^{2}+1\right) \omega_{n}^{2}-\frac{L_{1}}{L_{2}}-1
\end{array}\right]
$$

where $\alpha$ represents how far the third pole is located according to the dominant poles configuration [41]. The fitness function to determine the matrix $K$, considering the design parameters, is defined as

$$
F=\left|\frac{1}{\mathrm{MO}_{v}}\left(\mathrm{MO}_{v}-\mathrm{O}_{v}\right)\right|,
$$

where $\mathrm{MO}_{v}$ is the maximum allowed overshot, and $\mathrm{O}_{v}$ is the actual overshot. The control parameters $K=\left[\begin{array}{lll}156.6598 & 1689127.9947\end{array}\right]^{\top}$ and the precompensation gain $N=1845.7$ were estimated using this genetic approach. The compensated system achieved a settling time of $T_{S}=0.5593 \mathrm{~ms}$ and an overshoot of $4.9109 \%$. Table 4 summarizes the parameters used in the GA for tuning the poles placement method.

Table 4. GA and poles placement method.

\begin{tabular}{lc}
\hline GA Parameters & Value or Method \\
\hline Population Size & 100 \\
Max. Generations & 100 \\
Stop Criteria & 0.01 \\
Elitism & $5 \%$ of Population \\
Mutation & Aleatory Alteration \\
Crossover & Based on a Point \\
Undamped natural freq. $\left(\omega_{n}\right)$ & 11040 rad $/ \mathrm{s}]$ \\
Damping Factor $(\zeta)$ & 0.6901 \\
\hline
\end{tabular}

Finished the tuning process, the PI controller is designed through the poles placement method, and the simulation tests are then analyzed. The simulation parameters are given in Table 5.

Table 5. Parameters of MG model for PI controller.

\begin{tabular}{lcc}
\hline Parameters & Value & Units \\
\hline MG Voltage $\left(V_{D C}\right.$ Figure 2$)$ & 1000 & {$[\mathrm{~V}]$} \\
Filter Inductance & 2 & {$[\mathrm{mH}]$} \\
Filter Capacitance & 60 & {$[\mu \mathrm{F}]$} \\
Switching Frequency & 10 & {$[\mathrm{kHz}]$} \\
Proportional Constant $\left(K_{p}\right)$ & 0.82045 & \\
Integral Constant $\left(K_{i}\right)$ & 6668.4268 & \\
Balanced 3-phase linear loads & $20 / 20 / 20$ & {$[\Omega]$} \\
Unbalanced 3-phase linear loads & $20 / 5 / 1$ & {$[\Omega]$} \\
Fundamental Frequency & 60 & {$[\mathrm{~Hz}]$} \\
\hline
\end{tabular}

The simulation results were carried out on a set of interconnected nonlinear loads, which allowed testing the PI controller response under balanced and unbalanced nonlinear conditions. Figure 12 presents the PI controller performance driven by GA. 


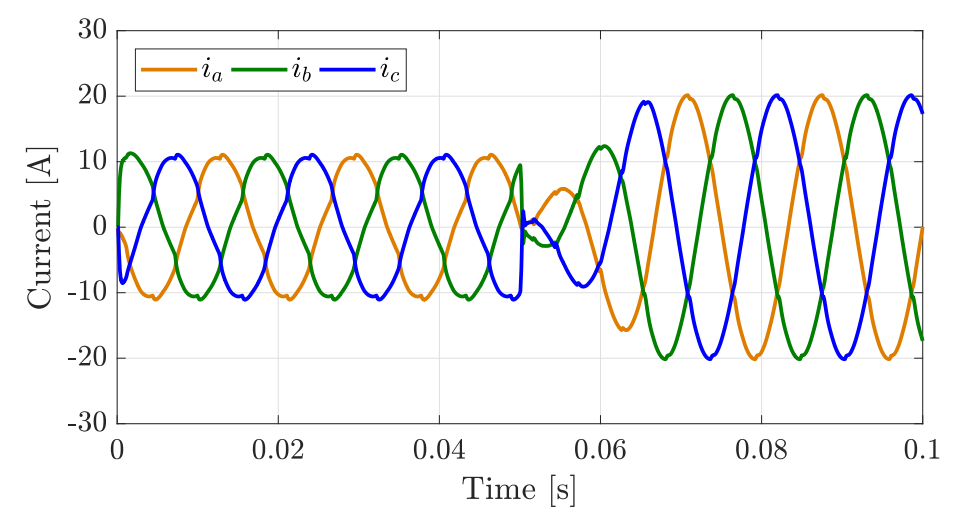

Figure 12. Compensation of PI controller driven by GA under balanced nonlinear conditions.

The control was able to compensate for the current distorted waveform, produced by balanced nonlinear loads. This methodology reduced the $\operatorname{THD}\left(i_{a}\right), \operatorname{THD}\left(i_{b}\right), \operatorname{THD}\left(i_{c}\right)$ indexes from 5.26\%, 5.26\% and $5.26 \%$ to $1.35 \%, 1.35 \%$ and $1.35 \%$. Likewise, the harmonic content reduction is shown in Table 6 (two and three columns) for this study case. Figure 13 shows a study case considering unbalanced nonlinear loads to verify the control quality face to harmonics and unbalanced actions of the MG control.

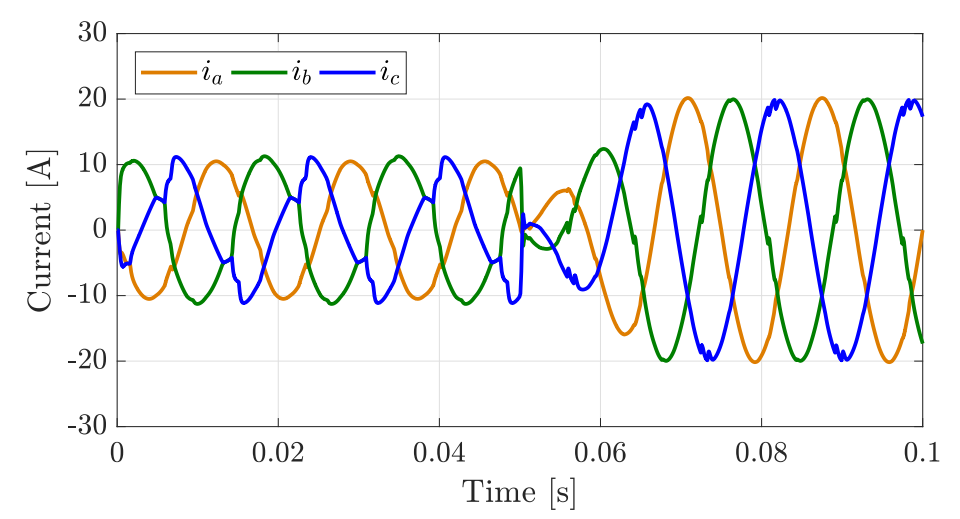

Figure 13. Compensation of PI controller driven by GA under balanced nonlinear conditions.

The numerical results generated a $\mathrm{CUF}=11 \%$ for unbalanced nonlinear loads, but the index is reduced to $0.6 \%$ once the controller is activated. Similarly, the $\operatorname{THD}\left(i_{a}\right), \operatorname{THD}\left(i_{b}\right)$, and $\operatorname{THD}\left(i_{c}\right)$ indexes of the current signals injected by MG are reduced from $5.61 \%, 12.09 \%$, and $18.69 \%$ to $1.30 \%, 2.50 \%$, and $2.55 \%$, respectively. In Table 6 (four and five columns), the harmonic content reduction corresponding to this study case is shown. In Figure 14, unbalanced linear and nonlinear loads were connected and simulated, which gave an improved performance for an unbalanced current compensation from $18 \%$ to $2 \%$.

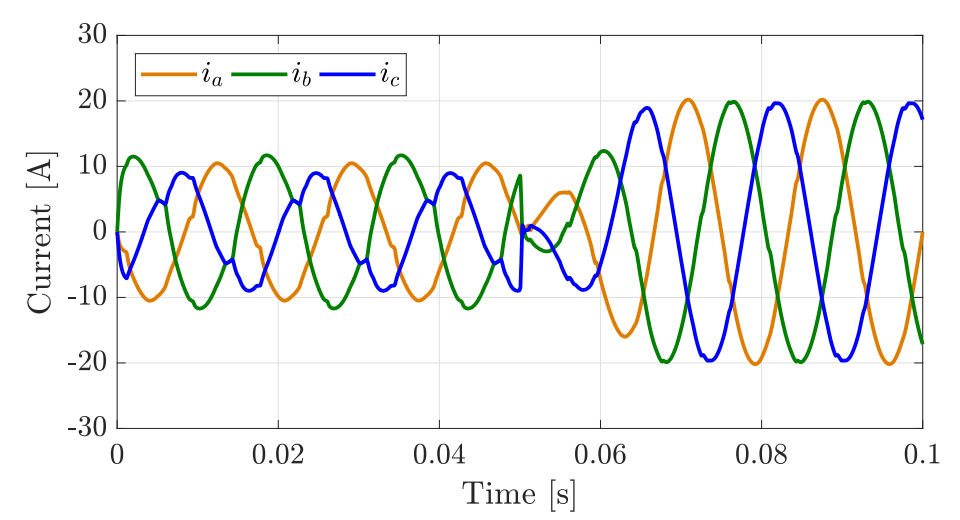

Figure 14. Compensation of PI controller driven by GA under unbalanced linear and nonlinear conditions. 
The harmonics were significantly reduced, which is depicted in Table 6 (six and seven columns). Likewise, a THD reduction was carried out, attenuating the $\operatorname{THD}\left(i_{a}, \operatorname{THD}\left(i_{b}\right)\right.$ and $\operatorname{THD}\left(i_{c}\right)$ indexes from $4.56 \%, 9.34 \%$, and $14.53 \%$ to $1.14 \%, 1.73 \%$, and $1.53 \%$, respectively.

Table 6. Harmonics content attenuated by PI controller driven by GA.

\begin{tabular}{|c|c|c|c|c|c|c|}
\hline \multirow[b]{2}{*}{$\begin{array}{l}\text { Harmonics } \\
\left(I_{a}^{L}, I_{b}^{L}, I_{c}^{L}\right)\end{array}$} & \multicolumn{2}{|c|}{ Balanced Nonlinear Loads } & \multicolumn{2}{|c|}{ Unbalanced Nonlinear Loads } & \multicolumn{2}{|c|}{$\begin{array}{l}\text { Unbalanced Linear and } \\
\text { Nonlinear Loads }\end{array}$} \\
\hline & $\begin{array}{l}\text { Original } \\
\text { Currents }\end{array}$ & $\begin{array}{l}\text { Controlled } \\
\text { Currents }\end{array}$ & $\begin{array}{l}\text { Original } \\
\text { Currents }\end{array}$ & $\begin{array}{l}\text { Controlled } \\
\text { Currents }\end{array}$ & $\begin{array}{l}\text { Original } \\
\text { Currents }\end{array}$ & $\begin{array}{c}\text { Controlled } \\
\text { Currents }\end{array}$ \\
\hline Third & $0.00,0.00,0.00$ & $\begin{array}{l}0.00,0.00 \\
0.00\end{array}$ & $0.48,1.06,1.53$ & $\begin{array}{l}0.11,0.22 \\
0.27\end{array}$ & $0.33,0.83,1.09$ & $\begin{array}{c}0.10,0.18, \\
0.20\end{array}$ \\
\hline Fifth & $0.44,0.44,0.44$ & $\begin{array}{l}0.15,0.15 \\
0.15\end{array}$ & $0.09,0.67,0.62$ & $\begin{array}{c}0.07,0.21 \\
0.18\end{array}$ & $0.18,0.57,0.39$ & $\begin{array}{c}0.08,0.17 \\
0.11\end{array}$ \\
\hline Seventh & $0.32,0.32,0.32$ & $\begin{array}{l}0.12,0.12 \\
0.12\end{array}$ & $0.17,0.37,0.46$ & $\begin{array}{l}0.08,0.18 \\
0.20\end{array}$ & $0.04,0.27,0.31$ & $\begin{array}{l}0.01,0.12 \\
0.12\end{array}$ \\
\hline Ninth & $0.00,0.00,0.00$ & $\begin{array}{l}0.00,0.00 \\
0.00\end{array}$ & $0.22,0.28,0.22$ & $\begin{array}{l}0.13,0.15 \\
0.08\end{array}$ & $0.19,0.23,0.12$ & $\begin{array}{l}0.11,0.12 \\
0.07\end{array}$ \\
\hline Eleventh & $0.13,0.13,0.13$ & $\begin{array}{l}0.09,0.09 \\
0.09\end{array}$ & $0.11,0.13,0.11$ & $\begin{array}{l}0.08,0.07 \\
0.04\end{array}$ & $0.08,0.15,0.15$ & $\begin{array}{l}0.05,0.09 \\
0.08\end{array}$ \\
\hline
\end{tabular}

\subsection{PI Control Design by the Poles Placement Method}

In this design, the LQR algorithm was implemented to estimate the $K$ matrix of feedback states. Besides, the penalization matrix $Q$ and effort control $R$ were assigned according to the requirements initially established using the poles placement method. The LQR control matrices and parameters assigned by the designer were determined as $\mathrm{R}=0.002$ and pre-compensation gain $\mathrm{N}=707.9018$,

$$
Q=\left[\begin{array}{ccc}
2.25 & 0 & 0 \\
0 & 1000 & 0 \\
0 & 0 & 0.04
\end{array}\right] \text {, and } K=\left[\begin{array}{c}
67.2952 \\
640.6066 \\
51.0547
\end{array}\right]^{\top}
$$

Numerical results gave a settling time $T_{S}=0.525 \mathrm{~ms}$ and an overshoot $=6.39 \%$. Next, the PI controller's $K_{p}$ and $K_{i}$ constants were calculated, combining the properties of LQR and PI controllers. The simulation parameters for this case study are shown in Table 7.

Table 7. Parameters of MG model for PI-LQR controller.

\begin{tabular}{lcc}
\hline Parameters & Value & Units \\
\hline MG Voltage $\left(V_{D C}\right.$ Figure 2$)$ & 500 & {$[\mathrm{~V}]$} \\
Filter Inductance & 2 & {$[\mathrm{mH}]$} \\
Filter Capacitance & 60 & {$[\mu \mathrm{F}]$} \\
Switching Frequency & 10 & {$[\mathrm{kHz}]$} \\
Proportional Constant $\left(K_{p}\right)$ & 0.15093 & \\
Integral Constant $\left(K_{i}\right)$ & 4003.3102 & \\
Balanced 3-phase linear loads & $20 / 20 / 20$ & {$[\Omega]$} \\
Unbalanced 3-phase linear loads & $20 / 5 / 1$ & {$[\Omega]$} \\
Fundamental Frequency & 60 & {$[\mathrm{~Hz}]$} \\
\hline
\end{tabular}

Similarly to the last two controllers, the MG behavior under balanced nonlinear loads, unbalanced nonlinear loads, and unbalanced linear and nonlinear loads connected at PCC was analyzed.

Figure 15 shows the controller performance under balanced nonlinear conditions, reducing the $\operatorname{THD}\left(i_{a}\right), \operatorname{THD}\left(i_{b}\right)$ and $\operatorname{THD}\left(i_{c}\right)$ indexes from $5.27 \%, 5.27 \%$ and $5.27 \%$ to $2.30 \%, 2.30 \%$ and $2.30 \%$ respectively. Harmonic reduction through PI controller by dominant poles is shown in Table 8 (two and three columns). 


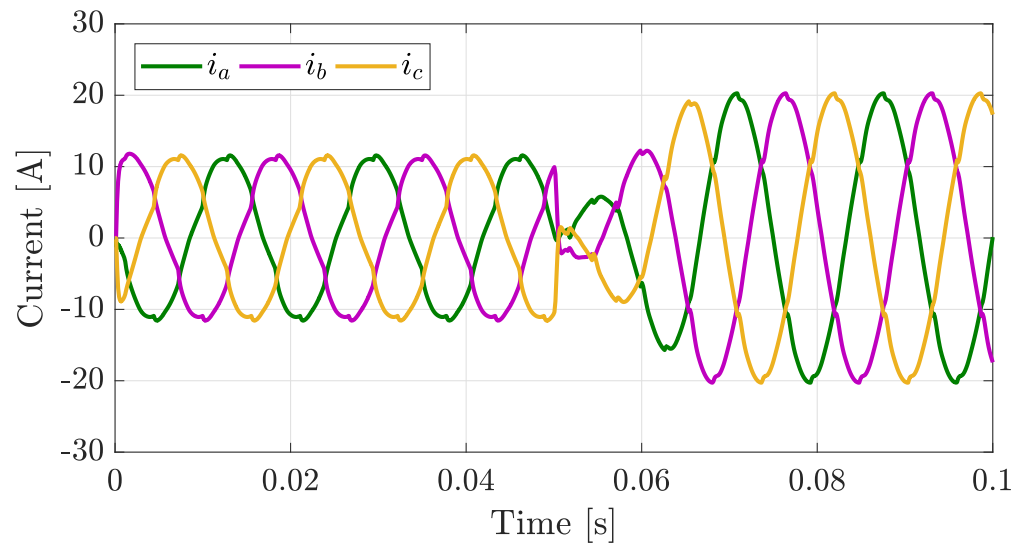

Figure 15. Compensation of PI controller tuned by poles placement method under balanced nonlinear conditions.

In the presence of unbalanced nonlinear loads, a CUF $=11 \%$ index is initially obtained, but those indexes are significantly reduced to 1\% under the MG control. Such an effect is shown in Figure 16.

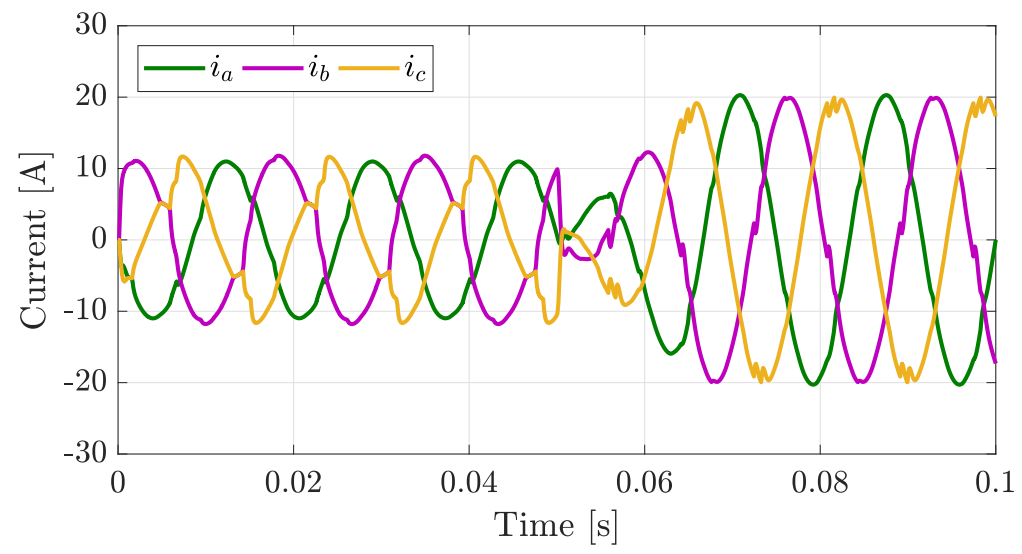

Figure 16. Compensation of PI controller tuned by poles placement method under unbalanced linear and nonlinear conditions.

In the same sense, a considerable harmonics mitigation was induced, which is given in Table 8 (four and five columns). Additionally, THD indexes of three phases were attenuated from $5.60 \%$, $12.05 \%$, and $18.65 \%$ to $2.27 \%, 4.22 \%$, and $4.22 \%$ for this study case. Figure 17 shows an unbalanced linear and nonlinear study case to verify the controller performance.

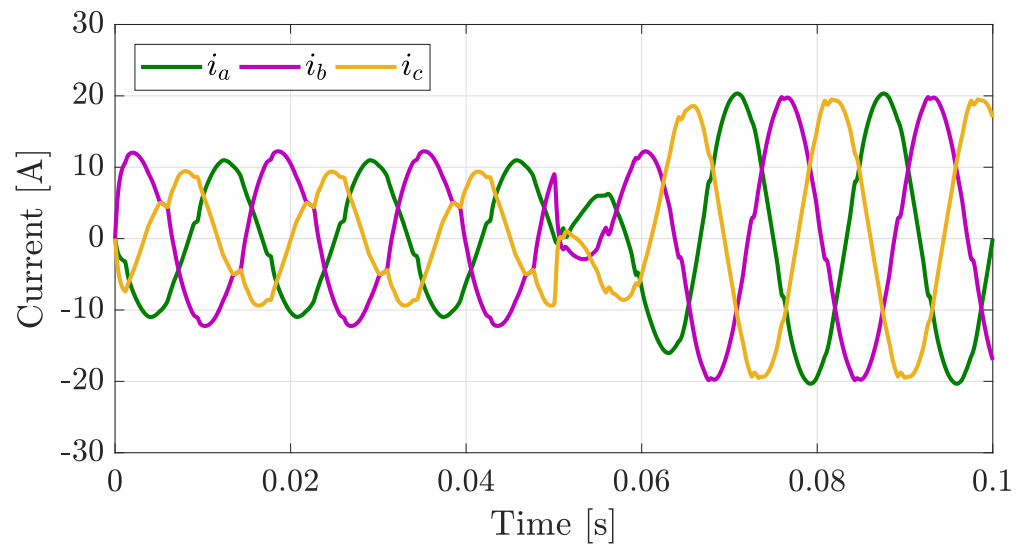

Figure 17. Compensation of PI controller tuned by poles placement method under unbalanced linear and nonlinear conditions. 
Table 8. Harmonics content attenuated by PI controller tuned by poles placement method.

\begin{tabular}{|c|c|c|c|c|c|c|}
\hline \multirow[b]{2}{*}{$\begin{array}{l}\text { Harmonics } \\
\left(I_{a}^{L}, I_{b}^{L}, I_{c}^{L}\right)\end{array}$} & \multicolumn{2}{|c|}{ Balanced Nonlinear Loads } & \multicolumn{2}{|c|}{ Unbalanced Nonlinear Loads } & \multicolumn{2}{|c|}{$\begin{array}{l}\text { Unbalanced Linear And } \\
\text { Nonlinear Loads }\end{array}$} \\
\hline & $\begin{array}{l}\text { Original } \\
\text { Currents }\end{array}$ & $\begin{array}{l}\text { Controlled } \\
\text { Currents }\end{array}$ & $\begin{array}{l}\text { Original } \\
\text { Currents }\end{array}$ & $\begin{array}{l}\text { Controlled } \\
\text { Currents }\end{array}$ & $\begin{array}{l}\text { Original } \\
\text { Currents }\end{array}$ & $\begin{array}{l}\text { Controlled } \\
\text { Currents }\end{array}$ \\
\hline Third & $0.00,0.00,0.00$ & $\begin{array}{l}0.00,0.00 \\
0.00\end{array}$ & $0.50,1.11,1.60$ & $\begin{array}{c}0.20,0.39 \\
0.47\end{array}$ & $0.35,0.86,1.14$ & $\begin{array}{c}0.18,0.32, \\
0.36\end{array}$ \\
\hline Fifth & $0.46,0.46,0.46$ & $\begin{array}{l}0.28,0.28 \\
0.28\end{array}$ & $0.09,0.70,0.64$ & $\begin{array}{l}0.13,0.39 \\
0.32\end{array}$ & $0.19,0.59,0.40$ & $\begin{array}{l}0.15,0.32 \\
0.20\end{array}$ \\
\hline Seventh & $0.34,0.34,0.34$ & $\begin{array}{l}0.23,0.23 \\
\quad 0.23\end{array}$ & $0.18,0.38,0.48$ & $\begin{array}{c}0.14,0.33 \\
0.37\end{array}$ & $0.04,0.28,0.32$ & $\begin{array}{l}0.01,0.22 \\
0.22\end{array}$ \\
\hline Ninth & $0.00,0.00,0.00$ & $\begin{array}{c}0.00,0.00 \\
0.00\end{array}$ & $0.23,0.29,0.11$ & $\begin{array}{c}0.25,0.28 \\
0.13\end{array}$ & $0.19,0.24,0.12$ & $\begin{array}{c}0.20,0.22, \\
0.12\end{array}$ \\
\hline Eleventh & $0.13,0.14,0.13$ & $\begin{array}{l}0.16,0.16 \\
0.16\end{array}$ & $0.11,0.13,0.11$ & $\begin{array}{c}0.15,0.13 \\
0.10\end{array}$ & $0.09,0.16,0.15$ & $\begin{array}{l}0.10,0.17 \\
0.14\end{array}$ \\
\hline
\end{tabular}

Under these conditions, the numerical results determine that MG reduced the current unbalanced index CUF from $18 \%$ to $2 \%$. The respective harmonic reduction is shown in Table 8 (six and seven columns). Besides, THD indexes $\left(i_{a}, i_{b}\right.$, and $\left.i_{c}\right)$ were reduced from $4.53 \%, 9.30 \%$, and $14.30 \%$ to $1.94 \%$, $3.08 \%$, and $2.68 \%$, respectively.

It is noteworthy that the harmonic content shown in Table 9 is extracted from the harmonic content from Tables 3, 6 and 8 when the controller in operation (see columns 3, 5, and 7). The energetic cost is associated with the MG Voltage $\left(\mathrm{V}_{D C}\right)$ parameter highlighted in Line 2 from Tables 2, 5 and 7. Numerical results in Table 9 allows determining that PI controller driven by GA obtained the best $\mathrm{THD}_{I}$ factor for the three study cases. Nevertheless, to reach this low distortion was necessary to use the higher DC voltage (i.e., $1000 \mathrm{~V}$ ), which could be highly restrictive and expensive in practice. On the other hand, the hybrid LQR-PI reached the lower energetic cost consuming only $311 \mathrm{~V}_{D C}$. Additionally, the measured harmonic distortion under this control action fulfills the allowed THD limits of $5 \%$ and is pretty close to the best results given by the PI controller driver by GA. Finally, the positive impact of saving energy by using the hybrid LQR-PI is fundamental in the selection criteria in an efficient MG system.

Table 9. Comparative analysis of THD and energetic cost obtained from the evaluated controllers.

\begin{tabular}{cccccccccccc}
\hline Control & \multicolumn{3}{c}{$\begin{array}{c}\text { Balanced Nonlinear } \\
\text { Loads (THD) }\end{array}$} & \multicolumn{2}{c}{$\begin{array}{c}\text { Unbalanced Nonlinear } \\
\text { Loads (THD) }\end{array}$} & \multicolumn{2}{c}{$\begin{array}{c}\text { Unbalanced Linear and } \\
\text { Nonlinear Loads (THD) }\end{array}$} & $\begin{array}{c}\text { MG } \\
\text { Voltage (V }\end{array}$ \\
& $\boldsymbol{i}_{\boldsymbol{a}}$ & $\boldsymbol{i}_{\boldsymbol{b}}$ & $\boldsymbol{i}_{\boldsymbol{c}}$ & $\boldsymbol{i}_{\boldsymbol{a}}$ & $\boldsymbol{i}_{\boldsymbol{b}}$ & $\boldsymbol{i}_{\boldsymbol{c}}$ & $\boldsymbol{i}_{\boldsymbol{a}}$ & $\boldsymbol{i}_{\boldsymbol{b}}$ & $\boldsymbol{i}_{\boldsymbol{c}}$ & \\
\hline Hybrid LQR-PI & 2.51 & 2.51 & 2.51 & 2.49 & 4.63 & 4.61 & 2.11 & 3.39 & 2.97 & $\mathbf{3 1 1}$ \\
PI Driven by GA & $\mathbf{1 . 3 5}$ & $\mathbf{1 . 3 5}$ & $\mathbf{1 . 3 5}$ & $\mathbf{1 . 3}$ & $\mathbf{2 . 5}$ & $\mathbf{2 . 5 5}$ & $\mathbf{1 . 1 4}$ & $\mathbf{1 . 7 3}$ & $\mathbf{1 . 5 3}$ & 1000 \\
PI+Poles Placement & 2.3 & 2.3 & 2.3 & 2.27 & 4.22 & 4.22 & 1.94 & 3.08 & 2.68 & 500 \\
\hline
\end{tabular}

Finally, Table 10 shows the comparison between research works found in literature and the proposed approach using related hybrid PI-LQR controllers.

This study proposed an efficient optimal control technique, combining the performance of LQR and PI controllers tuned by Genetic Algorithms using a reliable fitness function. The particular discriminant definition of the fitness function associated with the MG control scheme and appropriate implementation of the GA algorithm were fundamental to reach the required accuracy for estimating the controller design parameters. The proposal contributions were focused on using the hybrid PI-LQR controller driven by GA to regulate the energy supplied by the MG, showing the positive effects over typical compensating scenarios involving quality energy issues. Moreover, other controllers were designed to compare and evaluate which control scheme had the lowest energetic cost in its operation. The results can corroborate the effectiveness, robustness, and proper fitting of the hybrid PI-LQR 
controller according to the criteria as the simultaneous reduction on the negative sequence, harmonics, and energetic cost.

Table 10. Functional comparison of hybrid PI-LQR controllers.

\begin{tabular}{llll}
\hline Author & Fitness Function (F.F.) & Optimized Variables & Optimizer \\
\hline Lindiya et al. [18] & $\begin{array}{l}\text { F.F. based on } T_{s}, O_{v} \text {, rising time }\left(T_{r}\right), \\
\text { peak time }\left(T_{p}\right) \text {, and undershoot }\left(U_{v}\right)\end{array}$ & Cross regulation & GA \\
\hline Sen et al. [20] & $\begin{array}{l}\text { F.F. based on mean squared error using } \\
\text { the robot coordinates }\end{array}$ & $\begin{array}{l}\text { Coordinates of the reference } \\
\text { foot trajectory }\left(X_{r e f} \text { and } Y_{r e f}\right)\end{array}$ & $\begin{array}{l}\text { GA, PSO, } \\
\text { and GWO }\end{array}$ \\
\hline $\begin{array}{l}\text { Nagarkar et al. } \\
\text { [21] }\end{array}$ & $\begin{array}{l}\text { F.F. based on minimize control } \\
\text { force, RMS tyre deflection and RMS } \\
\text { suspension travel }\end{array}$ & $\begin{array}{l}\text { RMS acceleration }\left(A_{w}\right) \text {, and } \\
\text { fourth power vibration } \\
(V D V)\end{array}$ & GA \\
\hline Ibrahim et al. [22] & $\begin{array}{l}\text { F.F. based on } T_{s}, O_{v}, T_{r} \text { and error steady } \\
\text { state }(e s s)\end{array}$ & $\begin{array}{l}\text { Elevation, pitch, and travel } \\
\text { axis }\end{array}$ & GA \\
\hline Proposed method & $\begin{array}{l}\text { F.F. based on } T_{s}, O_{v} \\
\text { MG voltage or Input Source }\end{array}$ & GA \\
\hline
\end{tabular}

\section{Conclusions}

In this paper, three study cases were analyzed by considering important electrical features as low energetic cost, reduction of unbalanced currents, and harmonics attenuation. The three proposed tuning strategies allowed determining the correct controller parameters, as were requested by the parameter design. The second study case (PI controller driven by GA and rlocus design) obtained the best results considering mitigation of unbalanced current and harmonics reduction but demanding a high energetic cost that would require considerable photovoltaics configurations. In comparison, the parameters showed in Tables 2, 5 and 7, as well as the obtained results related to mitigation of harmonics and current unbalances, the proposed PI-LQR controller driven by GA, allowed fulfilling the international energy quality index normative and the design specifications. Besides, the proposed approach improved the MG power quality and accomplished a considerable magnitude reduction in the LQR parameters, $K$ matrix of feedback states, and MG voltage. Simulated results showed the effectiveness and robustness of the PI-LQR hybrid controller tuned by the GA, achieving an equilibrium on the initial electrical features established in the study cases.

Author Contributions: Conceptualization, G.H.V.-R. and L.R.M.-V.; Methodology, J.G.A.-C. and L.R.M.-V.; Software, G.T.-T., L.R.M.-V. and J.G.A.-C.; Validation, J.M.L.-G., M.A.I.-M. and G.T.-T.; Formal analysis, J.G.A.-C., M.A.I.-M. and L.R.M.-V.; Investigation, G.H.V.-R., L.R.M.-V. and J.G.A.-C.; Data curation, L.R.M.-V., M.A.I.-M. and G.T.-T.; Visualization, G.H.V.-R., M.A.I.-M. and J.M.L.-G.; Writing-original draft preparation, L.R.M.-V., and G.H.V.-R.; Writing—review and editing, J.G.A.-C. and J.M.L.-G. and G.T.-T.; Funding acquisition, J.G.A.-C. and J.M.L.-G. All authors have read and agreed to the published version of the manuscript.

Funding: The APC was funded by the Universidad de Guanajuato.

Acknowledgments: This project was fully supported by the Electronics and Electrical Departments of the Universidad de Guanajuato under the Program POA 2020, grant NUA 824646, and the Mexican Council of Science and Technology CONACyT, grant number $863547 / 491067$.

Conflicts of Interest: The funders had no role in the design of the study; in the collection, analyses, or interpretation of data; in the writing of the manuscript, or in the decision to publish the results. 


\section{References}

1. Hirsch, A.; Parag, Y.; Guerrero, J. Microgrids: A review of technologies, key drivers, and outstanding issues. Renew. Sustain. Energy Rev. 2018, 90, 402-411, doi:10.1016/j.rser.2018.03.040. [CrossRef]

2. Banerji, A.; Sen, D.; Bera, A.K.; Ray, D.; Paul, D.; Bhakat, A.; Biswas, S.K. Microgrid: A review. In Proceedings of the 2013 IEEE Global Humanitarian Technology Conference: South Asia Satellite (GHTC-SAS), Trivandrum, India, 23-24 August 2013; pp. 27-35, doi:10.1109/GHTC-SAS.2013.6629883. [CrossRef]

3. Blaabjerg, F.; Teodorescu, R.; Liserre, M.; Timbus, A.V. Overview of Control and Grid Synchronization for Distributed Power Generation Systems. IEEE Trans. Ind. Electron. 2006, 53, 1398-1409, doi:10.1109/TIE.2006.881997. [CrossRef]

4. DOE. 2012 DOE Microgrid Workshop; Summary Report; U.S. Department of Energy: Chicago, IL, USA, 2012.

5. Parhizi, S.; Lotfi, H.; Khodaei, A.; Bahramirad, S. State of the art in research on microgrids: A review. IEEE Access 2015, 3, 890-925, doi:10.1109/ACCESS.2015.2443119. [CrossRef]

6. Li, Y.W.; Vilathgamuwa, D.M.; Loh, P.C. A grid-interfacing power quality compensator for three-phase three-wire microgrid applications. In Proceedings of the 2004 IEEE 35th Annual Power Electronics Specialists Conference (IEEE Cat. No.04CH37551), Aachen, Germany, 20-25 June 2004; Volume 3, pp. 2011-2017, doi:10.1109/PESC.2004.1355426. [CrossRef]

7. Wang, F.; Duarte, J.L.; Hendrix, M.A.M. Grid-Interfacing Converter Systems With Enhanced Voltage Quality for Microgrid Application-Concept and Implementation. IEEE Trans. Power Electron. 2011, 26, 3501-3513, doi:10.1109/TPEL.2011.2147334. [CrossRef]

8. IEEE Std 1159-2009 (Revision of IEEE Std 1159-1995). IEEE Recommended Practice for Monitoring Electric Power Quality; Standard; IEEE Power \& Energy Society: New York, NY, USA, 2009; pp. 1-94, doi:10.1109/IEEESTD.2009.5154067. [CrossRef]

9. Hamzeh, M.; Karimi, H.; Mokhtari, H. Harmonic and Negative-Sequence Current Control in an Islanded Multi-Bus MV Microgrid. IEEE Trans. Smart Grid 2014, 5, 167-176. [CrossRef]

10. Shi, H.; Zhuo, F.; Yi, H.; Geng, Z. Control strategy for microgrid under three-phase unbalance condition. J. Mod. Power Syst. Clean Energy 2016, 4, 94-102, doi:10.1007/s40565-015-0182-3. [CrossRef]

11. Azevedo, G.; Rocabert Delgado, J.; Cavalcanti, M.; Neves, F.; Rodriguez, P. A Negative-sequence Current Injection Method To Mitigate Voltage Imbalances In Microgrids. Eletrônica de Potência 2011, 16, 296-303, doi:10.18618/REP.20114.296303. [CrossRef]

12. Foad, N.; Mohsen, H.; Matthias, F. Unbalanced Current Sharing Control in Islanded Low. Energies 2018, 11, 2776, doi:10.3390/en11102776. [CrossRef]

13. Dasgupta, S.; Mohan, S.N.; Sahoo, S.K.; Panda, S.K. Lyapunov Function-Based Current Controller to Control Active and Reactive Power Flow From a Renewable Energy Source to a Generalized Three-Phase Microgrid System. IEEE Trans. Ind. Electron. 2013, 60, 799-813. [CrossRef]

14. Sinha, T.; Ray, P.; Salkuti, S. Protection Coordination in Microgrid Using Fault Current Limiters. J. Green Eng. 2018, 8, 125-150. doi:10.13052/jge1904-4720.822. [CrossRef]

15. Surender Reddy, S.; Park, J.; Jung, C. Optimal Operation of Microgrid Using Hybrid Differential Evolution and Harmony Search Algorithm. Front. Energy 2016, 10, 355-362, doi:10.1007/s11708-016-0414-x. [CrossRef]

16. Lotfollahzade, M.; Akbarimajd, A.; Javidan, J. Design LQR and PID Controller for Optimal Load Sharing of an Electrical Microgrid. Int. Res. J. Appl. Basic Sci. 2013, 4, 704-712.

17. Savaghebi, M.; Jalilian, A.; Vasquez, J.C.; Guerrero, J.M. Secondary control for voltage quality enhancement in microgrids. IEEE Trans. Smart Grid 2012, 3, 1893-1902, doi:10.1109/TSG.2012.2205281. [CrossRef]

18. Lindiya, S.; Subashini, N.; Vijayarekha, K. Cross Regulation Reduced Optimal Multivariable Controller Design for Single Inductor DC-DC Converters. Energies 2019, 12, 477, doi:10.3390/en12030477. [CrossRef]

19. Momoh, J.; Reddy, S. Value of Hardware-In-Loop for Experimenting Microgrid Performance System Studies. In Proceedings of the IEEE PES PowerAfrica Conference, Livingstone, Zambia, 28 June-3 July 2016; pp. 199-203, doi:10.1109/PowerAfrica.2016.7556600. [CrossRef] 
20. Şen, M.A.; Kalyoncu, M. Grey Wolf Optimizer Based Tuning of a Hybrid LQR-PID Controller for Foot Trajectory Control of a Quadruped Robot. Gazi Univ. J. Sci. 2019, 32, 674-684.

21. Nagarkar, M.; Bhalerao, Y.; Patil, G.V.; Patil, R.Z. Multi-Objective Optimization of Nonlinear Quarter Car Suspension System-PID and LQR Control. Procedia Manuf. 2018, 20, 420-427. doi:10.1016/j.promfg.2018.02.061. [CrossRef]

22. Mohammed, I.; Abdullah, A.I. Elevation, pitch and travel axis stabilization of 3DOF helicopter with hybrid control system by GA-LQR based PID controller. Int. J. Electr. Comput. Eng. (IJECE) 2020, 10, 1868, doi:10.11591/ijece.v10i2.pp1868-1884. [CrossRef]

23. Verdugo, C.; Tarraso, A.; Candela, J.I.; Rocabert, J.; Rodriguez, P. Synchronous Frequency Support of Photovoltaic Power Plants with Inertia Emulation. In Proceedings of the 2019 IEEE Energy Conversion Congress and Exposition (ECCE), Baltimore, MD, USA, 29 September-3 October 2019; pp. 4305-4310, doi:10.1109/ECCE.2019.8913200. [CrossRef]

24. Liu, F.; Zha, X.; Zhou, Y.; Duan, S. Design and research on parameter of LCL filter in three-phase grid-connected inverter. In Proceedings of the 2009 IEEE 6th International Power Electronics and Motion Control Conference, Wuhan, China, 17-20 May 2009; pp. 2174-2177.

25. Shen, G.; Xu, D.; Cao, L.; Zhu, X. An Improved Control Strategy for Grid-Connected Voltage Source Inverters With an LCL Filter. IEEE Trans. Power Electron. 2008, 23, 1899-1906. [CrossRef]

26. Gamit, B.R.; Vyas, S.R. Harmonic Elimination in Three Phase System By Means of a Shunt Active Filter. Int. Res. J. Eng. Technol. (IRJET) 2018, 5, 313-322.

27. Escudero, R.; Noel, J.; Elizondo, J.; Kirtley, J. Microgrid fault detection based on wavelet transformation and Park's vector approach. Electric Power Syst. Res. 2017, 152, 401-410, doi:10.1016/j.epsr.2017.07.028. [CrossRef]

28. Lewis, F.L.; Draguna Vrabie, V.L.S. Optimal Control, 3rd ed.; John Wiley \& Sons, Inc.: Hoboken, NJ, USA, 2012; p. 553.

29. Fadali, M.S.; Visioli, A. State Feedback Control. In Digital Control Engineering, 2nd ed.; Fadali, M.S., Visioli, A., Eds.; Academic Press: Boston, MA, USA, 2013; Chapter 9, pp. 351-397, doi:10.1016/B978-0-12-394391-0.00009-5. [CrossRef]

30. White, M.S.; Flockton, S.J. Genetic Algorithms for Digital Signal Processing; Springer: New York, NY, USA, 1994; Volume 865, pp. 291-303, doi:10.1007/3-540-58483-8_22. [CrossRef]

31. Robandi, I.; Nishimori, K.; Nishimura, R.; Ishihara, N. Optimal feedback control design using genetic algorithm in multimachine power system. Int. J. Electr. Power Energy Syst. 2001, 23, 263-271, doi:10.1016/S0142-0615(00)00062-4. [CrossRef]

32. Črepinšek, M.; Liu, S.H.; Mernik, M. Exploration and Exploitation in Evolutionary Algorithms: A Survey. ACM Comput. Surv. 2013, 45, doi:10.1145/2480741.2480752. [CrossRef]

33. Ogata, K. Modern Control Engineering, 5th ed.; Prentice Hall: Upper Saddle River, NJ, USA, 2010; p. 905.

34. Chen, T.-H.; Yang, C.-H.; Hsieh, T.-Y. Case Studies of the Impact of Voltage Imbalance on Power Distribution Systems and Equipment. In Proceedings of the 8th WSEAS International Conference on Applied Computer and Applied Computational Science, 2009; Volume 8, pp. 461-465. Available online: https://www. scribd.com/document/49242179/Case-Studies-of-the-Impact-of-Voltage-Imbalance-on-Power (accessed on 28 May 2020).

35. Mousavi, S.Y.M.; Jalilian, A.; Savaghebi, M.; Guerrero, J.M. Flexible compensation of voltage and current unbalance and harmonics in microgrids. Energies 2017, 10, 1568, doi:10.3390/en10101568. [CrossRef]

36. Savaghebi, M.; Jalilian, A.; Vasquez, J.C.; Guerrero, J.M. Autonomous Voltage Unbalance Compensation in an Islanded Droop-Controlled Microgrid. IEEE Trans. Ind. Electron. 2013, 60, 1390-1402, doi:10.1109/TIE.2012.2185914. [CrossRef]

37. ANSI/NEMA MG 1-2016Motors and Generators; Standard; American National Standard Institute: Rosslyn, VI, USA, 2016.

38. Share Pasand, M.M. Harmonic Aggregation Techniques. J. Electr. Electron. Eng. 2015, 3, 117-120, doi:10.11648/j.jeee.20150305.13. [CrossRef]

39. Mazin, H.E.; Xu, W. Harmonic cancellation characteristics of specially connected transformers. Electr. Power Syst. Res. 2009, 79, 1689-1697, doi:10.1016/j.epsr.2009.07.006. [CrossRef] 
40. IEC 61000-4-7:2002 Testing and Measurement Techniques-General Guide on Harmonics and Interharmonics Measurements and Instrumentation, for Power Supply Systems and Equipment Connected Thereto; Standard; International Electrotechnical Commission: Geneva, Switzerland, 2002.

41. Nise, N.S. Control Systems Engineering, 6th ed.; John Wiley \& Sons, Inc.: Hoboken, NJ, USA, 2011; p. 1001.

(C) 2020 by the authors. Licensee MDPI, Basel, Switzerland. This article is an open access article distributed under the terms and conditions of the Creative Commons Attribution (CC BY) license (http:/ / creativecommons.org/licenses/by/4.0/). 